\title{
The Beneficial Potential of Genetically Modified Stem Cells in the Treatment of Stroke: a Review
}

\author{
Mohammad Saied Salehi ${ }^{1}$. Anahid Safari ${ }^{2}$ (D) Sareh Pandamooz ${ }^{2} \cdot$ Benjamin Jurek $^{3} \cdot$ Etrat Hooshmandi $^{1}$. \\ Maryam Owjfard $^{1} \cdot$ Mahnaz Bayat $^{1} \cdot$ Seyedeh Shaghayegh Zafarmand ${ }^{1} \cdot$ Jaleel A. Miyan ${ }^{4}$. Afshin Borhani-Haghighi ${ }^{1}$
}

Accepted: 26 April 2021 / Published online: 25 May 2021

(C) The Author(s), under exclusive licence to Springer Science+Business Media, LLC, part of Springer Nature 2021

\begin{abstract}
The last two decades have witnessed a surge in investigations proposing stem cells as a promising strategy to treat stroke. Since growth factor release is considered as one of the most important aspects of cell-based therapy, stem cells over-expressing growth factors are hypothesized to yield higher levels of therapeutic efficiency. In pre-clinical studies of the last 15 years that were investigating the efficiency of stem cell therapy for stroke, a variety of stem cell types were genetically modified to over-express various factors. In this review we summarize the current knowledge on the therapeutic efficiency of stem cell-derived growth factors, encompassing techniques employed and time points to evaluate. In addition, we discuss several types of stem cells, including the recently developed model of epidermal neural crest stem cells, and genetically modified stem cells over-expressing specific factors, which could elevate the restorative potential of naive stem cells. The restorative potential is based on enhanced survival/differentiation potential of transplanted cells, apoptosis inhibition, infarct volume reduction, neovascularization or functional improvement. Since the majority of studies have focused on the short-term curative effects of genetically engineered stem cells, we emphasize the need to address their long-term impact.
\end{abstract}

Keywords Cell therapy $\cdot$ MCAO $\cdot$ Stroke $\cdot$ Genetic engineering $\cdot$ Growth factors $\cdot$ Stem cells

Anahid Safari

a_safari@sums.ac.ir

1 Clinical Neurology Research Center, Shiraz University of Medical Sciences, Shiraz, Iran

2 Stem Cells Technology Research Center, Shiraz University of Medical Sciences, Shiraz, Iran

3 Institute of Molecular and Cellular Anatomy, University of Regensburg, Regensburg, Germany

4 Faculty of Biology, Division of Neuroscience \& Experimental Psychology, The University of Manchester, Manchester, UK

\section{Introduction}

Stroke is considered as one of the main causes of disability and death all around the world [1, 2]. Reperfusion modalities, such as mechanical thrombectomy and thrombolysis, have been applied for treating ischemic stroke as the most common type of stroke. However, some issues reduce their clinical application, such as development of hemorrhagic transformation, a narrow therapeutic window, and restricted availability [3]. Therefore, seeking new alternatives with fewer limitations and higher efficacy, especially for therapy resistant patients is of paramount necessity.

Reduced oxygen levels in the infarct region following stroke eventually leads to activation of a wide variety of growth factor-related signaling cascades, which exert 
neuroprotective, anti-inflammatory and anti-apoptotic effects $[4,5]$. Nevertheless, endogenous growth factors are insufficient to induce cell survival, neurogenesis and angiogenesis. Hence, it has been suggested that the increment of growth factors by protein or gene therapy could be a potential strategy for stroke. Although, the restorative effects of various growth factors have been investigated for stroke treatment [4], their short half-life has limited their direct application.

The last two decades have witnessed a surge in investigations proposing stem cells as a promising strategy to treat stroke (Fig. 1). Stem cells, due to their multipotency property, might be able to replace apoptotic/necrotic cells and/or stimulate intrinsic repair mechanisms and protective pathways. Stem cell therapy following stroke has the potential to improve neuroplasticity by regulating angiogenesis as well as neurogenesis, ameliorate cognitive dysfunction, and enhance functional recovery. Because of several advantages, such as possible autologous transplantation, reduced risk of tumorigenicity and not having ethical concerns, adult stem cells are widely used in pre-clinical and clinical trials to treat various neurological disorders including cerebral ischemia $[6,7]$.

In biomedical research in general, and the field of stroke in particular, mesenchymal stem cells (MSCs) are considered as the most commonly employed stem

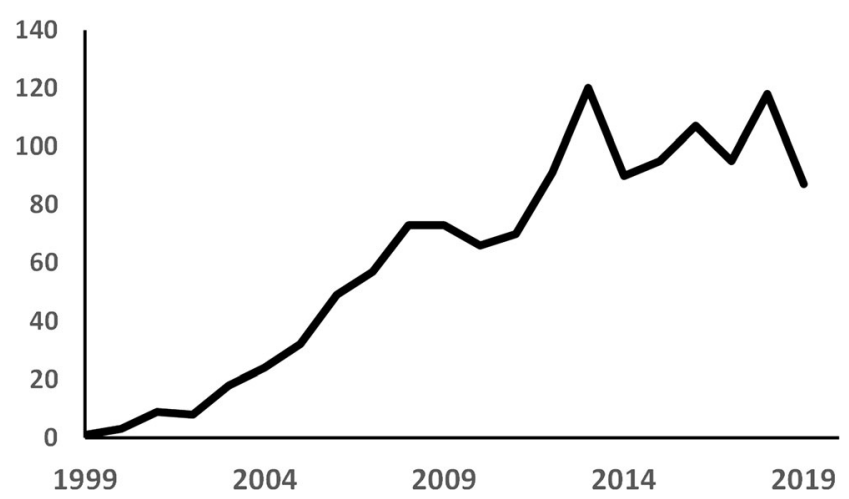

Fig. 1 Number of published manuscripts per year listed in PubMed from 1999 to 2019 based on "Stem cell" and "Stroke" MeSH terms cell that can be isolated from different sources, such as bone marrow, placenta, umbilical cord, dental, muscle, fat, and skin [8]. MSCs are characterized by low cell turnover, multipotency, immunomodulation, and paracrine actions. MSCs are able to differentiate into mesenchymal-, as well as nonmesenchymal cell lineages, such as hepatocytes, fibroblasts, adipocytes, chondrocytes, osteoblasts, cardiomyocytes, glia, and neurons in microenvironmental dependent manners [9]. These stem cells are able to modulate immune responses, by suppressing inflammatory cytokine secretion and stimulating lymphocytes. Also, they exert paracrine actions by secreting a variety of trophic factors, like insulin growth factor-1, basic fibroblast growth factor, vascular endothelial growth factor, brain derived neurotrophic factor, and hepatocyte growth factor. Mesenchymal stem cells [8, 10-15] from different sources including bone marrow [16, 17] adipose tissue [18] and umbilical cord [19] are used to treat cerebral ischemia in numerous investigations and their effectiveness and mechanisms of action have been thoroughly reviewed in recent years.

Although endogenous neurogenesis in the dentate gyrus and the subventricular zone increase following cerebral ischemia, this process is insufficient. Since neural stem cells (NSCs) are able to differentiate into different neural cells, such as oligodendrocytes, astrocytes, and neurons, it has been proposed that transplanted NSCs can be considered as unlimited source of newly formed neural cells, which are able integrate into ischemic brain tissue. Therefore, besides MSCs, neural stem cells are used in a plethora of studies in the context of stroke [20-26]. Furthermore, by graft-to-host communications following NSCs transplantation, a series of interactions will occur in order to ameliorate the devastating conditions following stroke. These events include promoted angiogenesis and neurogenesis, neuroinflammation reduction, and blood-brain barrier preservation.

Moreover, other types of stem cells, such as bone marrow mononuclear cells [27, 28], induced pluripotent stem cells [29-32], dental pulp stem cells [33, 34], menstrual blood-derived stem cells $[35,36]$, and epidermal neural crest stem cells [37] have been evaluated as a potential treatment of stroke. The release of growth 
factors by stem cells is considered as one of the most important therapeutic aspects of cell-based therapy [38]. Therefore, the hypothesis has been proposed that the combination of stem cell and gene therapy might potentiate the efficiency. Consequently, stem cells that overexpress growth factors show a higher level of restorative potential (Fig. 2).

In pre-clinical investigations during the last 15 years, different types of mesenchymal and neural stem cells, which are discussed in the current review (Table 1) were genetically engineered to over-express various genes in the context of stroke. Furthermore, since the obtained results are highly time and method dependent, we discussed them with a focus on the employed techniques and time points.

\section{Over-expression of Neurotrophins}

\section{Brain-derived Neurotrophic Factor (BDNF)}

BDNF, one of the most well-studied members of the neurotrophin family, is considered as the neurotrophin with the highest expression level in the adult central nervous system. BDNF plays fundamental roles in synaptic remodeling and brain plasticity, neurite extension, neuronal development and cell survival. Following stroke, it has been reported that BDNF expression in the infarct region is permanently reduced [79], and single allele deficiency for BDNF (+/-) resulted in larger infarct area [80]. Furthermore, it has been shown that BDNF treatment led to a reduction in lesion size [81, 82] and improved functional motor performance [82-84]; however, due to the short half-life of BDNF, this therapeutic approach does not provide long-term effects. Therefore, in order to provide long-lasting effects of BDNF post-ischemia, one possible strategy is to transplant stem cells that stably over-express this protein.

As the first published experiment using genetically modified stem cells to treat stroke, Kurozumi et al. [39] evaluated therapeutic effects of human bone marrow mesenchymal stem cells (BM-MSCs), genetically modified to over-express BDNF (MSCs ${ }^{\mathrm{BDNF}}$ ). The stem cells were transplanted into the striatum of male rats, one day after $90 \mathrm{~min}$ middle cerebral artery occlusion (MCAO). Limb placement and treadmill tests showed functional improvements at days 8 and 15 after stoke in rats that received $\mathrm{BM}-\mathrm{MSCs}{ }^{\mathrm{BDNF}}$ compared to the non-transplanted (control) group. Also, T2-weighted imaging (T2WI, see Box 1) on days 7 and 14 post-MCAO revealed a prominent infarct volume reduction in the $\mathrm{MSCs}^{\mathrm{BDNF}}$ group, compared to controls. Wild-type MSCs neither improved functional recovery, nor reduced infarct size at the evaluated time points. $\mathrm{MSC}^{\mathrm{BDNF}}$ also decreased the number of terminal deoxynucleotidyltransferase dUTP nick-end labeling (TUNEL)-positive apoptotic cells in the ischemic boundary zone one week after stroke compared to control. Again, wild-type MSCs did not show any therapeutic effect. At this time point, some transplanted stem cells expressed neuronal (NeuN) or glial (GFAP) markers and MSCs ${ }^{\mathrm{BDNF}}$ showed features similar to MSCs. Hence, curative potential of $\mathrm{MSCs}^{\mathrm{BDNF}}$ might be independent of their differentiation potential.

Moreover, Nomura et al. [40] evaluated the efficacy of systemic delivery of human MSCs transfected with the BDNF gene in a male rat model of permanent MCAO (pMCAO). In their study, stem cells were intravenously injected $6 \mathrm{~h}$ after induction of unilateral pMCAO to evaluate if cellular delivery of BDNF by hMSCs could affect functional recovery and infarct volume. The T2WI showed wild-type hMSCs decreased the size of the lesion area on days 1, 3, and 7 after pMCAO, compared to control group; BDNF overexpression enhanced the positive outcome compared to hMSCs at day seven. In addition, 2,3,5-triphenyltetrazolium chloride (TTC, see Box 1) staining showed similar results one-week post-MCAO. Behavioral performance, as assessed by treadmill stress test, revealed both MSCs and $\mathrm{MSCs}^{\mathrm{BDNF}}$ elicited a functional improvement compared to controls; however, the effect was greater in MSCs $^{\text {BDNF }}$ group. Lastly, a small number of implanted cells expressed FOX-3 (NeuN, $8 \%$ ), neurofilament (NF, $\sim 7 \%$ ) or glial fibrillary acidic protein (GFAP, $7.5 \%$ ) proteins at day 7 , revealing neuronal and glial developmental lines. 


\begin{tabular}{|c|c|c|}
\hline Technique & Features & Sample figure \\
\hline TTC staining & $\begin{array}{l}\text { The 2,3,5-triphenyltetrazolium chloride (TTC) } \\
\text { staining is the most frequently used tool to } \\
\text { macroscopically differentiate viable tissue from } \\
\text { infarction. This technique is fast and cheap and the } \\
\text { results can be obtained in less than an hour. In the } \\
\text { viable tissue, the colorless TTC is enzymatically } \\
\text { reduced to a red formazan product by } \\
\text { dehydrogenases, which are most abundant in } \\
\text { mitochondria. Hence, the injured area without viable } \\
\text { mitochondria remains unstained. However, transient } \\
\text { dehydrogenase activity impairment can lead to over- } \\
\text { estimation of the infarct area }[85,86] \text {. }\end{array}$ & \\
\hline Nissl staining & $\begin{array}{l}\text { Cresyl violet staining is one of the commonly used } \\
\text { techniques to visualize experimental brain } \\
\text { infarctions. Cresyl violet stains Nissl substance in } \\
\text { neurons. TTC and Nissl staining are showing a high } \\
\text { degree of correlation in infarct areas; however Nissl } \\
\text { staining is rather time consuming [87]. }\end{array}$ & \\
\hline HE staining & $\begin{array}{l}\text { Hematoxylin / eosin (HE) staining has been used for } \\
\text { more than a century to recognize different cell types, } \\
\text { as well as morphological changes. Hematoxylin } \\
\text { stains nucleic acids, while eosin stains proteins } \\
\text { nonspecifically. Although HE stainings have been } \\
\text { employed to detect infarct areas in some studies, its } \\
\text { lack of specificity constitutes a disadvantage } \\
\text { compared to Nissl or TTC stainings. }\end{array}$ & \\
\hline MRI & $\begin{array}{l}\text { Unlike all above mentioned techniques that are } \\
\text { executed at the end of each set of experiments, } \\
\text { magnetic resonance imaging (MRI) can be } \\
\text { performed during the experiments to assess the } \\
\text { infarct area. Diffusion-weighted imaging (DWI), a } \\
\text { form of MR imaging, is more useful for lesion } \\
\text { volume detection during the acute infarction phase } \\
\text { (usually } 3 \text { to } 6 \text { hours after stroke). T2 weighted } \\
\text { image (T2WI) is one of the basic pulse sequences in } \\
\text { MRI, and is usually used to detect infarct areas, days } \\
\text { to weeks after stroke [88]. }\end{array}$ & \\
\hline
\end{tabular}




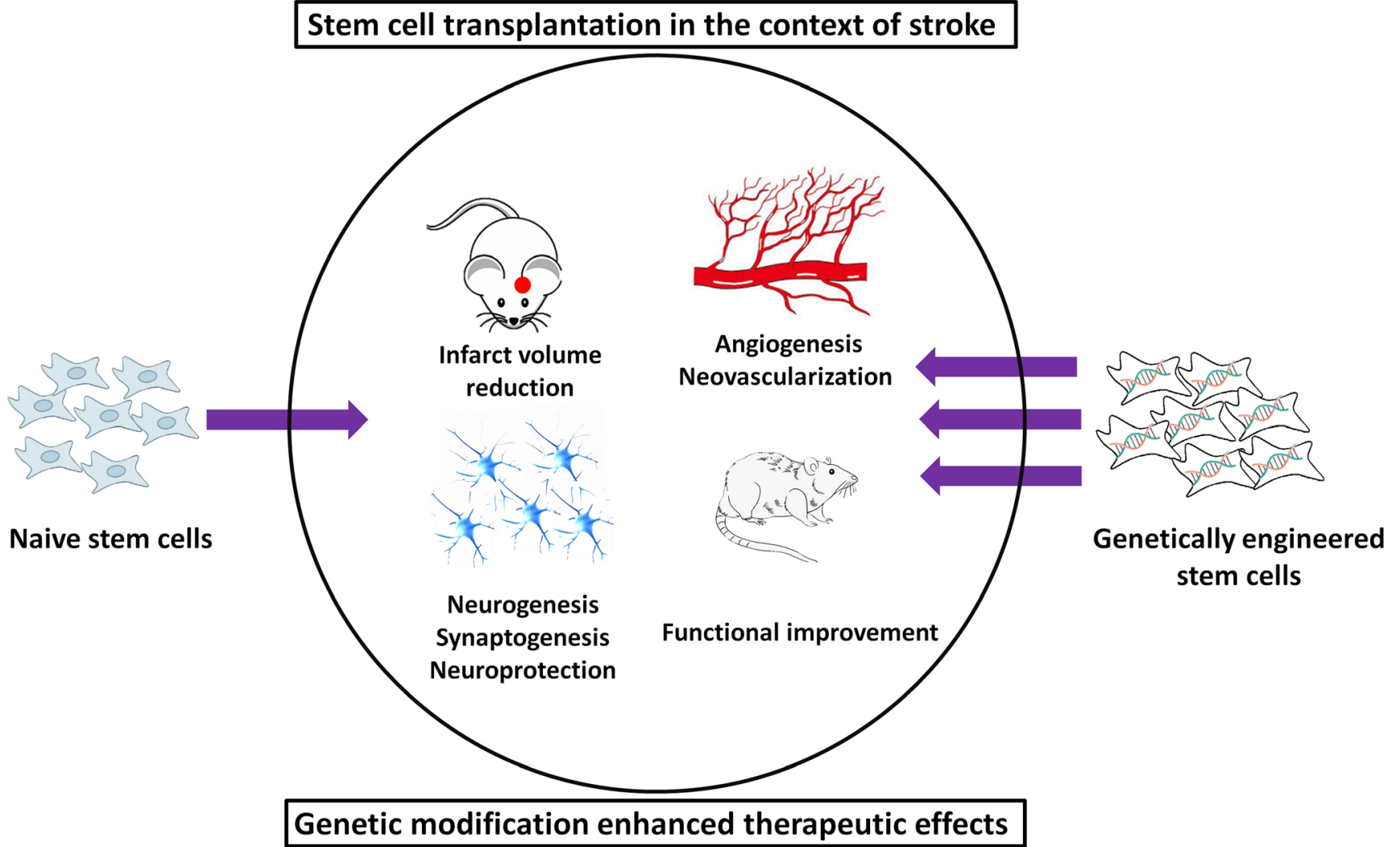

Fig. 2 Genetic modification of stem cells enhanced their therapeutic effects in animal models of stroke

Another approach by Lee et al. [41] made use of stable BDNF overexpressing human neural stem cell (hNSCs) line (HB1.F3), in a mouse model of intracerebral hemorrhage (ICH). ICH was induced by injection of collagenase type IV into the striatum and seven days later stem cells were administrated into the ipsilateral striatum. Stem cells improved motor function, which was assessed by rotarod and limb placement tests (See Box 2), up to eight weeks post-transplantation. $\mathrm{NSCs}^{\mathrm{BDNF}}$ enhanced motor outcome compared to NSCs. Over-expression of BDNF increased survival of transplanted cells in the striatum by 1.6 -fold after two weeks, and 3 -fold after 8 weeks post administration compared to NSCs. At 2- and 8-weeks post-transplantation, large portion of $\mathrm{NSCs}^{\mathrm{BDNF}}$ expressed the light and heavy chain of neurofilament, MAP2 and GFAP in the vicinity of the hemorrhagic core. Also, immunostaining for von Willebrandt factor $(\mathrm{vWF})$ revealed $\mathrm{NSCs}{ }^{\mathrm{BDNF}}$ increased number of microvessels by $2-3$ fold compared to NSCs and 6-8 fold compared to the control group. Transplanted stem cells reduced the number of apoptotic (TUNEL positive) cells in the hemorrhage core border areas, and the number of apoptotic cells was decreased in the group receiving BDNF over-expressing stem cells. Although ICH increased proapoptotic protein expression of caspase 3, p21 and p53 in the ipsilateral hemisphere, stem cells and more specifically $\mathrm{NSCs}^{\mathrm{BDNF}}$ prevented over-expression of those mentioned proapoptotic proteins, 2 and 8 weeks after transplantation. In line with that, the pro- survival signaling molecule Aktl as well as the antiapoptotic $\mathrm{Bcl}-2$ protein were elevated. Therefore, it seems that $\mathrm{NSCs}^{\mathrm{BDNF}}$ could exert neoangiogenic and neuroprotective effects in $\mathrm{ICH}$ injury sites.

Zhu and colleagues [42] evaluated the effectiveness of rat NSCs transfected with the human BDNF gene. Stem cells were labelled with bromodeoxyuridine (BrdU) and intrastriatally implanted three days after 120 min MCAO. The neurological function deficit was assessed using the neurological severity score (NSS) 2 to 12 weeks after transplantation, with no significant differences being observed between the experimental groups in the first 6 weeks. However, $\mathrm{NSCs}^{\mathrm{BDNF}}$ improved functional recovery from week 8 on compared to non-transplanted control, and improved functional recovery compared to non-transfected NSCs from week 10 on. To track the transplanted stem cells, doublestaining against BrdU and BDNF was performed one week after transplantation and obtained results revealed that around $25 \%$ of implanted cells survived in the ischemic areas and expressed BDNF protein. Also, doublestaining against BrdU and 


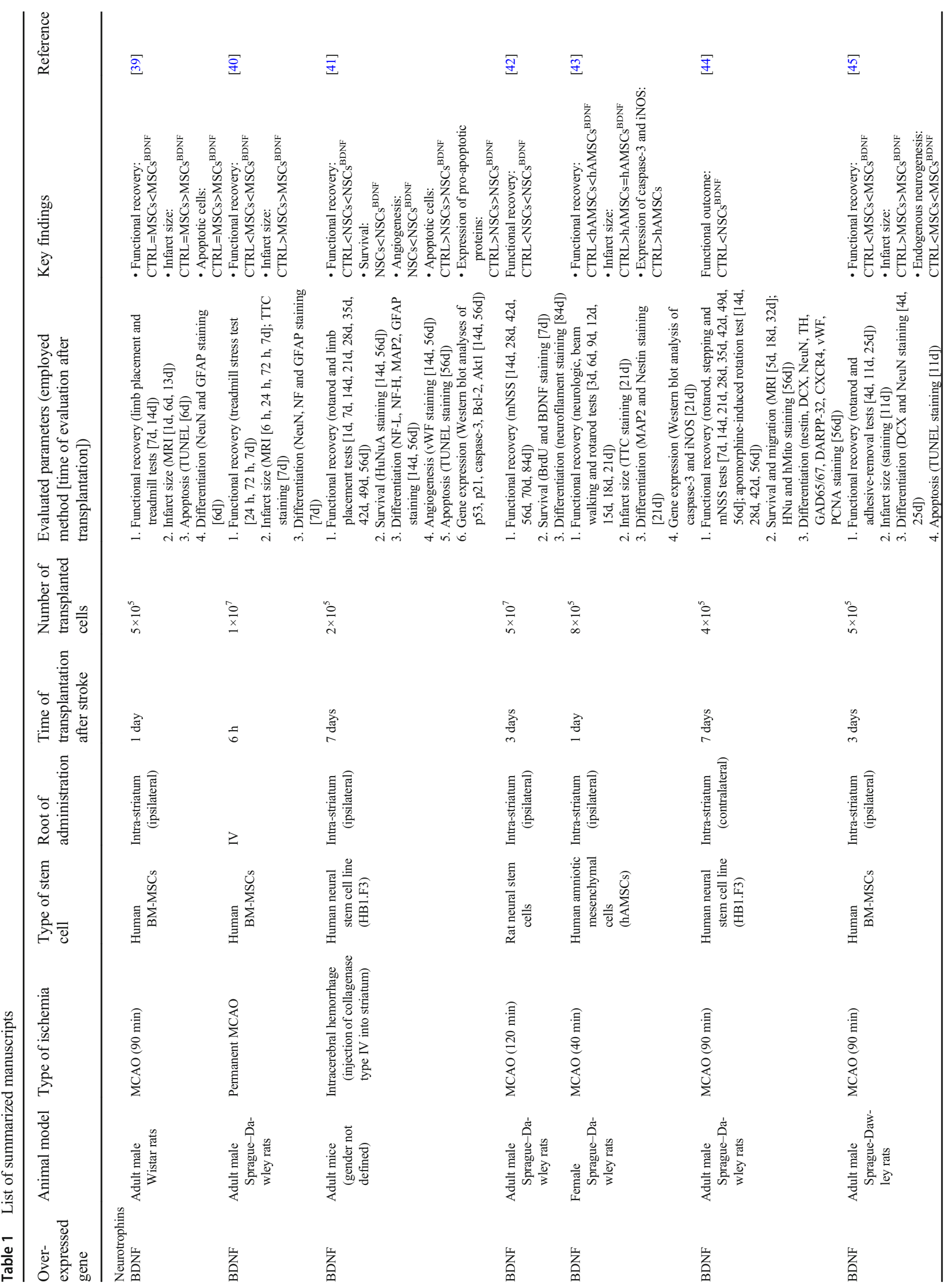




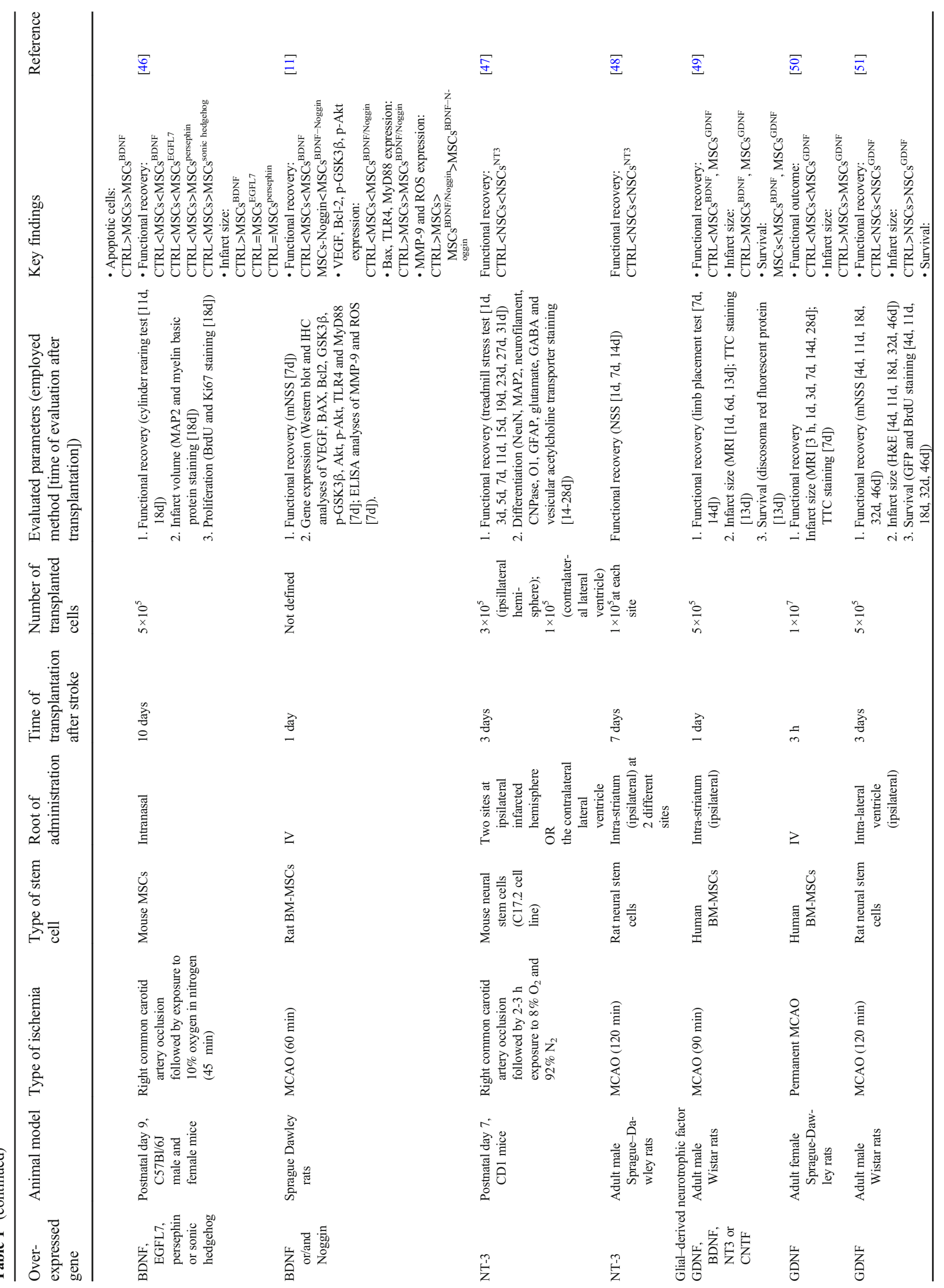




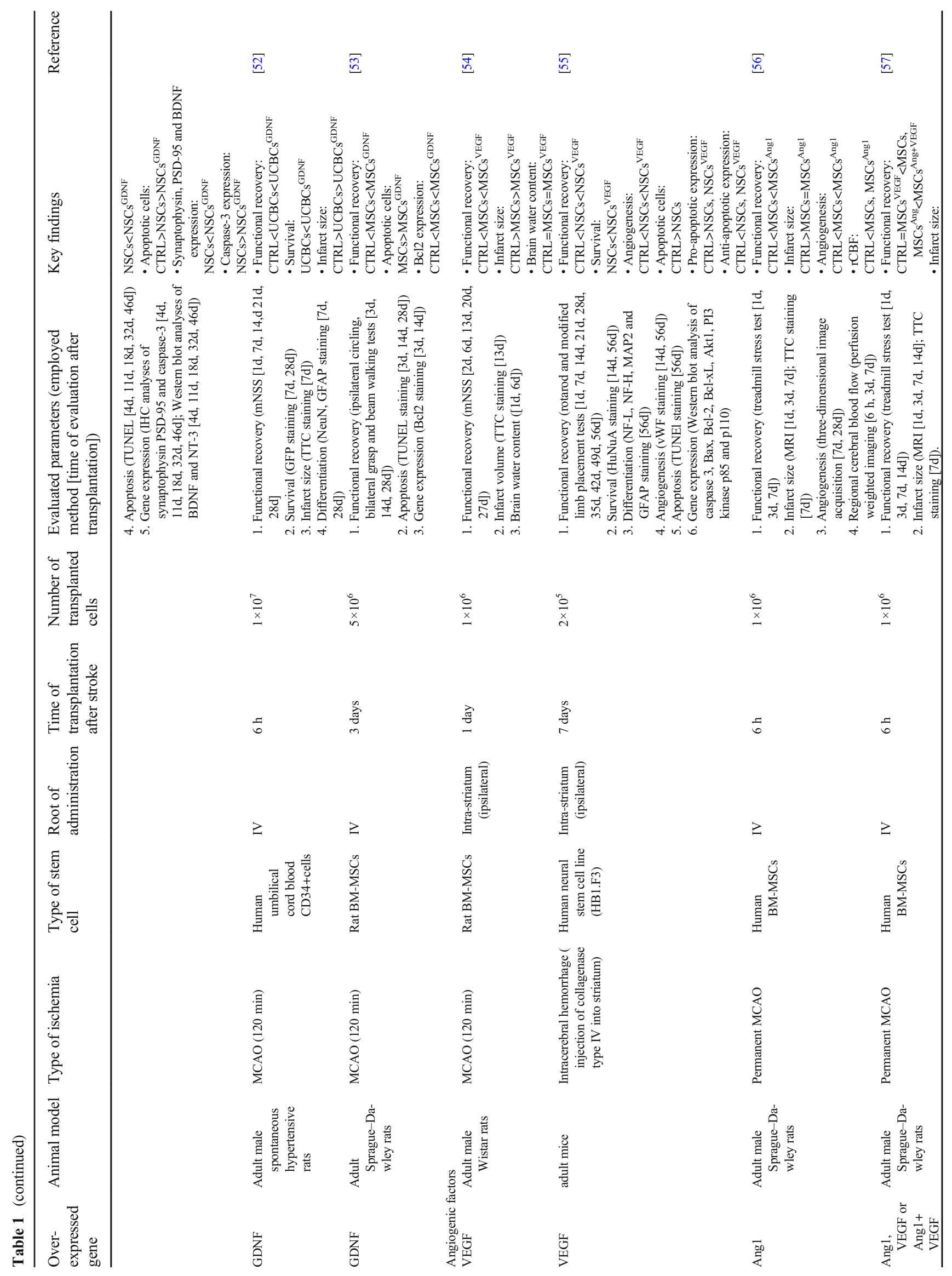




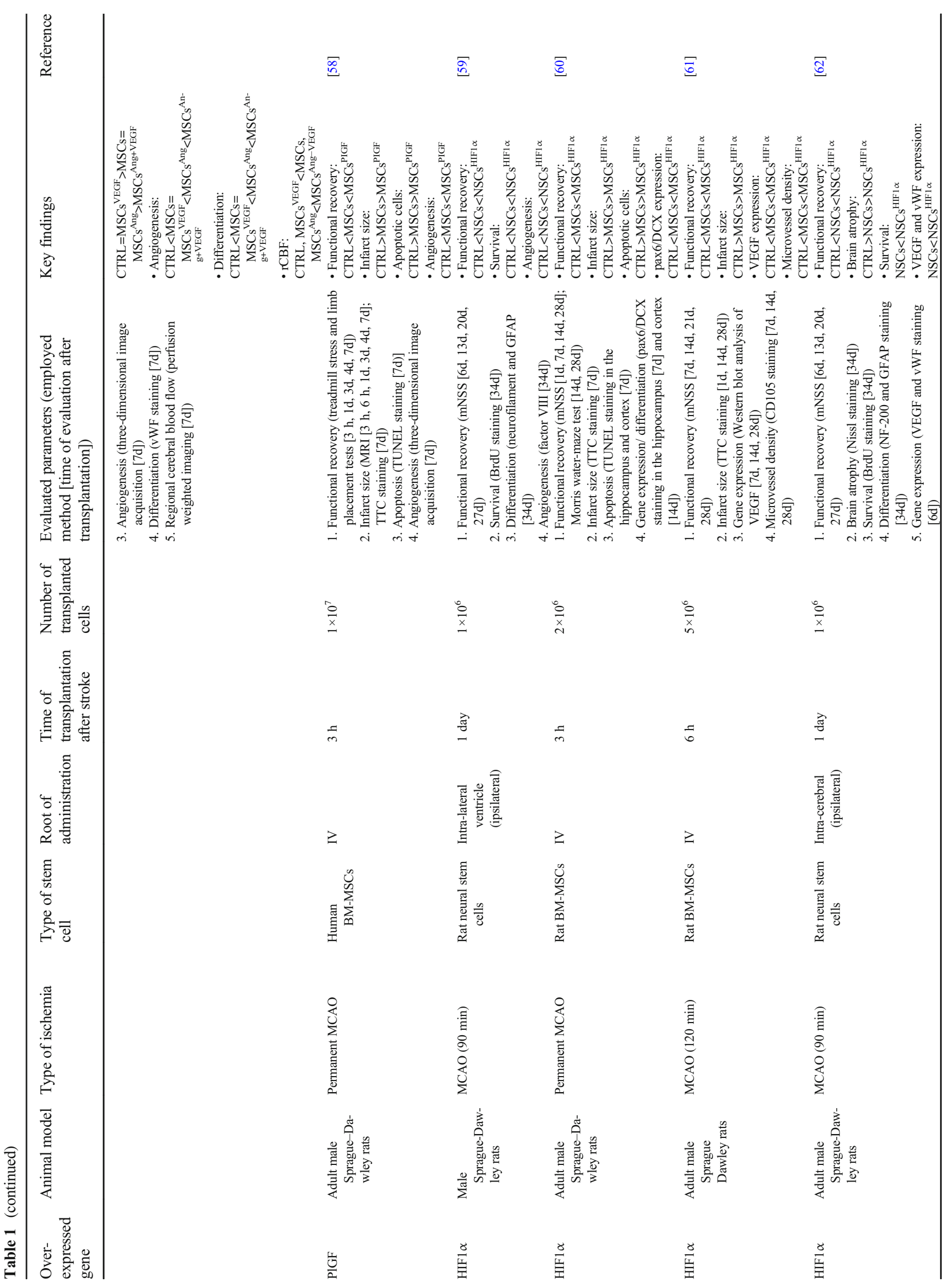




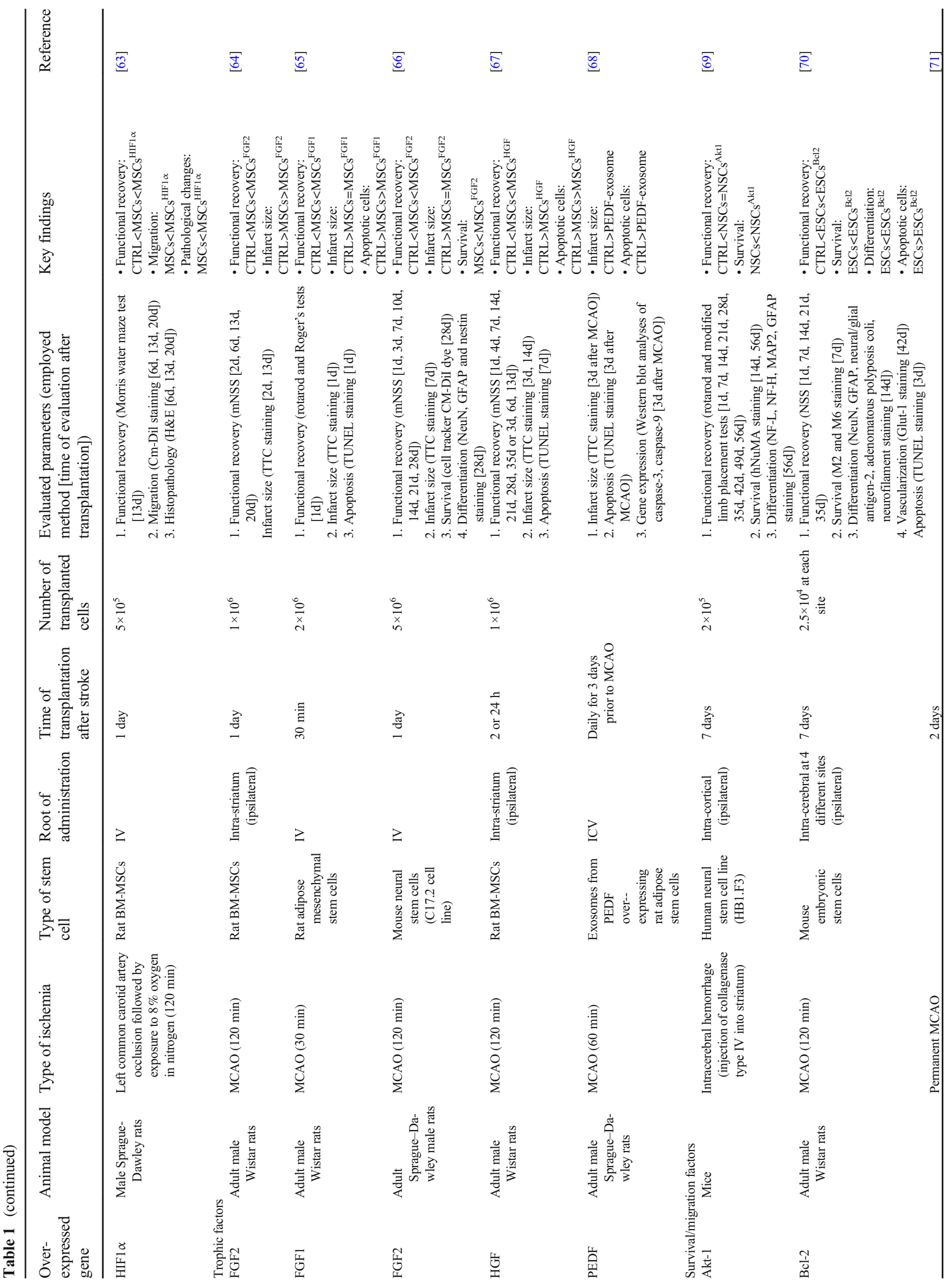




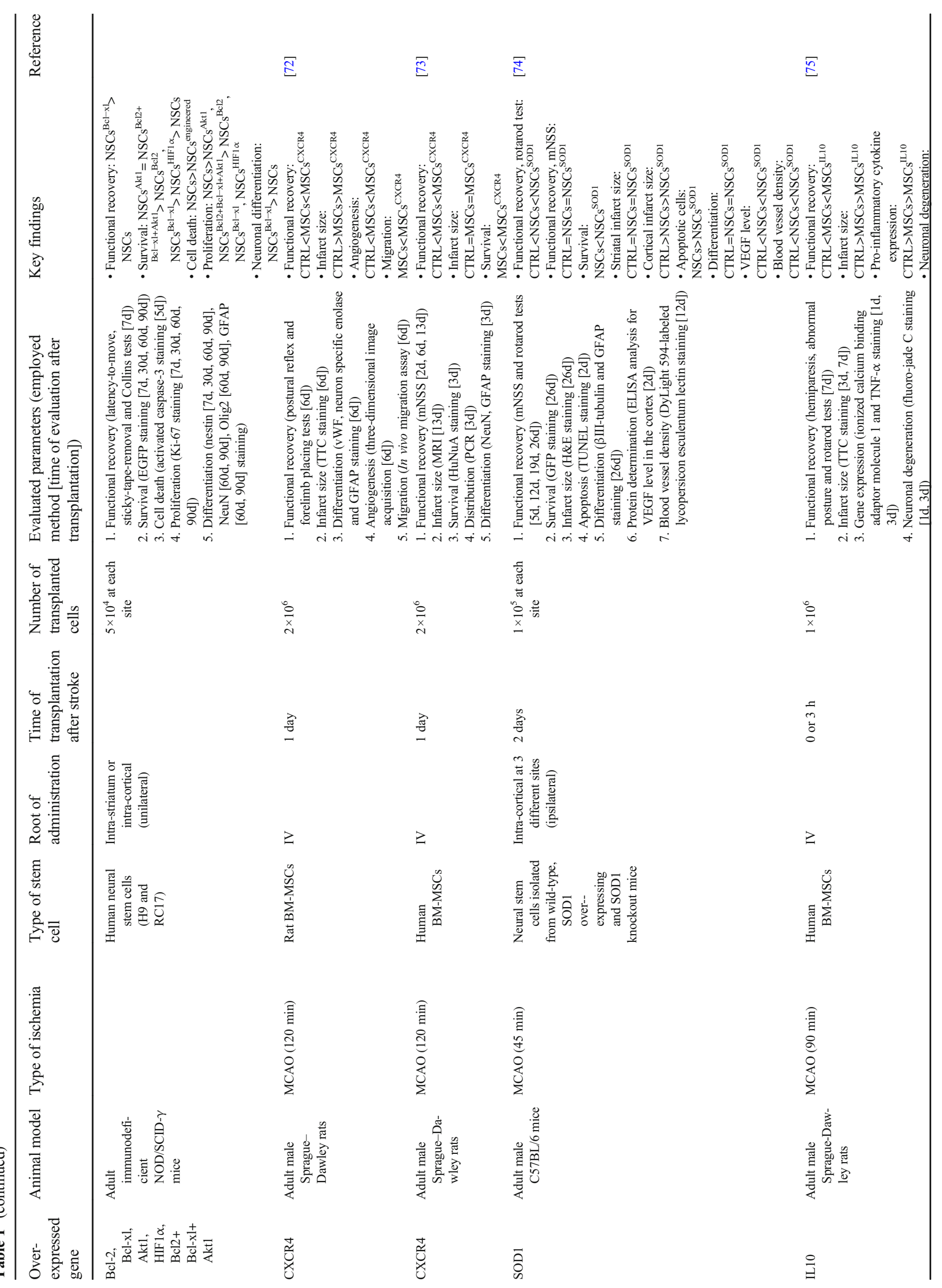




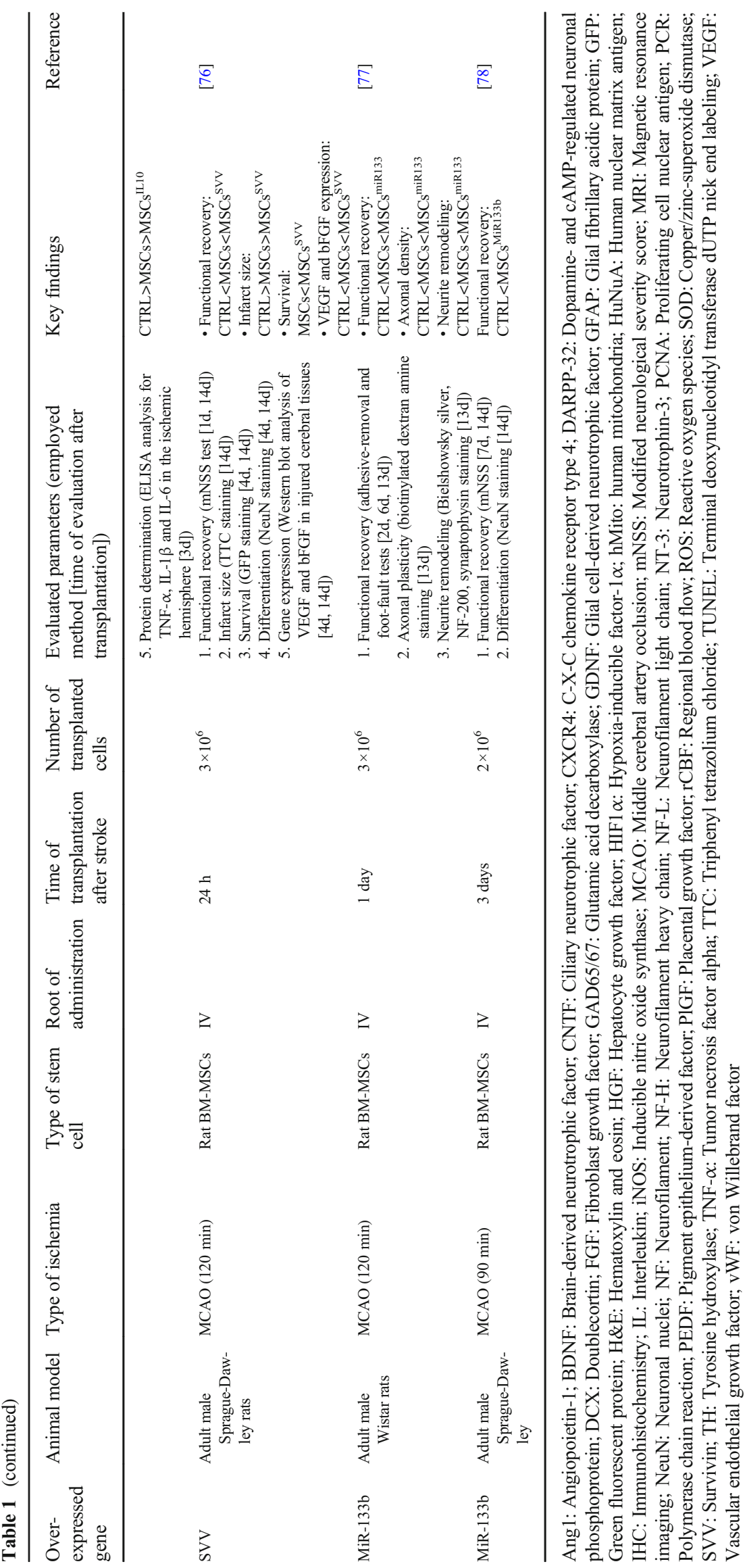


neurofilament, 12 weeks after implantation, showed that 20 $38 \%$ of transplanted NSCs ${ }^{\mathrm{BDNF}}$ were able to differentiate into neurons. However, the authors did not provide any data regarding the differentiation ability of naive NSCs.

In another study, Tao et al. [43] employed human amniotic membrane-derived mesenchymal stem cells (hAMSCs) that were transfected with the BDNF gene. Stem cells implanted into the dorsolateral striatum of female rats subjected to a transient 40 min MCAO one day after stroke. On day 21 after hAMSCs therapy, some transplanted cells expressed nestin as neuronal progenitor marker and MAP2 as neuronal marker. At this time point, hAMSCs reduced infarct volume without significant differences between modified and non-modified hAMSCs, and decreased caspase- 3 and iNOS protein expression. Based on beam-walking and rotarod tests (see box 2 for more details) from days 6 to 21 , stem cells improved the functional recovery compared to controls and hAMSCs ${ }^{\mathrm{BDNF}}$ induced functional motor improvements at earlier time points and/or with greater effects.

Box 2: Behavioral tests usually employed to evaluate neurological function

Behavioral test
Adhesive-removal test

Beam-walking test

Bilateral grasp test

Cylinder rearing test

Foot-fault test

Hemiparesis score

Ipsilateral circling test

Limb placement test

Modified neurological severity score (mNSS) test

\section{Description}

In this test, adhesive paper dots are used as tactile stimuli on the wrist of each forelimb and the time necessary for animals to remove the tape is recorded.

In this test, the animal is placed on a beam, and beam walking is graded from easily traversed the beam, to unable to walk on the beam.

In this test, the animal's paws is placed on the edge of a box and strength of the hemiparetic paw is graded from grasp well, to unable to grasp with forepaw.

In this test, the animal is placed in a transparent cylinder and the weight-bearing forepaw(s) to contact the wall during a full rear is recorded.

In this test, the total number of steps (movement of each forelimb) that an animal uses to cross the grid and the total numbers of foot faults for each forelimb is recorded.

In this test, the hind limbs of each animal are gently extended with a round-tipped forceps and the flexor response is scored.

In this test, the extent of circling to the side of the infusion is graded from no circling to always circling.

In this test, four limbs of animals are evaluated by using the edges and top of a counter top.

NSS is a composite of balance, reflex, sensory, and motor tests and the higher scores represent increased severity in injury.

Morris Water Maze test

In this test, the animal is placed in a tank of water with a hidden platform. During training trials, the latency to find the platform location is recorded. During experimental trials, the platform is removed, and the percentage of time spent in the quadrant that normally contains the platform is compared to the time spent in other quadrants.

Posture score

In this test, the animal is suspended by the tail and forelimb flexion and body twisting is scored.

Roger's tests

In this test, the movement of an animal is scored from no deficit, to not responding to stimulation.

Rotarod test

In this test, the animal is placed on a rotating rod and the speed of the rotation is gradually increased. This test usually uses to assess sensorimotor coordination.

Stepping test

In this test, a wooden ramp with a length around $1 \mathrm{~m}$ connect a platform to the animal's home cage. Initiation time, stepping time and step length is recorded when the animals move from the platform to their home cage.

Treadmill (stress) test

In this test, animals are placed on an accelerating treadmill and they should run and maintain their median position on the belt as its speed steadily increases. In the treadmill stress test, to avoid foot-shocks, animals have to move forward.

Furthermore, Chang and co-workers [44] evaluated the therapeutic and neurogenic ability of human NSC line (HB1.F3) overexpressing BDNF following transplantation into the contralateral striatum on day 7 after stroke in a male rat model of $90 \mathrm{~min}$ MCAO. In this study, just effects of BDNF-overexpressing NSCs were compared to non-transplanted control. Up to eight weeks post implantation, behavioral improvements from week 3 in the rotarod- as well as stepping-tests were obtained. From week 4 on, improvements in the modified neurological severity score (mNSS) test were recorded. From day 5 after contralateral administration, transplanted stem cells were detected in the infarct area and eight weeks after transplantation, a high portion of NSCs ${ }^{\mathrm{BDNF}}$ migrated to the ipsilateral damaged area. At this time point, some of the transplanted cells were nestin-, doublecortin (DCX, as migrating neuroblasts)- or MAP2-positive, which shows that some implanted stem cells preserved their stemness potential, while others differentiated toward the neuronal lineage. In addition, some transplanted stem cells co-stained with tyrosine hydroxylase or glutamic acid decarboxylase 65/67 (GAD65/67), indicating differentiation of the transplanted stem cells into dopaminergic and GABAergic neurons, respectively. Also, some migrated cells expressed dopamine- and cAMP-regulated neuronal 
phosphoprotein (DARPP-32) as striatal projection neurons marker. Furthermore, some NSCs ${ }^{\mathrm{BDNF}}$ transplanted cells expressed CXCR4 as chemokine receptor 4 marker that can response to inflammatory signals, such as stromal derived factor-1, following cerebral ischemia.

Jeong and colleagues [45] investigated the effects of intrastriatal transplantation of BDNF modified human bone marrow (BM)-MSCs, three days after 90 min MCAO. MSCs ${ }^{\text {BDNF }}$ improved the functional recovery from day 14 on up until day 28 after implantation, based on the adhesive-removal test. However, rotarod stress test revealed functional improvements in the MSCs $^{\text {BDNF }}$ group just on day 28. Transplanted stem cells decreased the infarct area, which was assessed by TTC staining 14 days after stroke, and BDNF over-expression led to more reduction in lesion size. Immunostaining 7 and 28 days after MCAO showed that cell therapy increased the number of BrdU, BrdU/ DCX and BrdU/NeuN positive cells in the sub-ventricular zone indicating enhanced endogenous neurogenesis. For all of these parameters, MSCs ${ }^{\text {BDNF }}$ had greater outcome. Stem cell transplantation decreased the number of TUNEL positive cells in the ischemic lesion, and the number of apoptotic cells was much lower in the BDNF over-expressing group. Then, MSCs ${ }^{\mathrm{BDNF}}$ could enhance endogenous neurogenesis and protect neural cells from apoptotic death.

van Velthoven et al. [46] investigated the curative potential of mouse MSCs that were genetically modified to overexpress BDNF, epidermal growth factor-like 7 (EGFL7), persephin, and sonic hedgehog in the perinatal mouse model of hypoxia-ischemia. Cerebral ischemia was induced by right common carotid artery occlusion, followed by $45 \mathrm{~min}$ exposure to $10 \%$ oxygen and stem cells were administrated intranasally 10 days later. Based on the cylinder rearing test, $\mathrm{MSCs}^{\mathrm{BDNF}}$ and MSCs ${ }^{\text {EGFL7 }}$ improved motor function compared to control and MSCs groups at days 21 and 28 after ischemia. Persephin over-expression just improved functional recovery on day 21 compared to control. Mice treated with $\mathrm{MSCs}^{\text {sonic hedgehog }}$ showed even decreased functional improvements compared to MSCs. In this study, infarct volume was assessed at day 28 by immunostaining against microtubule-associated protein and myelin basic protein to visualize gray and white matters, respectively. Obtained data revealed that MSCs, MSCs ${ }^{\mathrm{BDNF}}$ and $\mathrm{MSCs}^{\text {persephin }}$ decreased infarct size compared to control, while MSCs ${ }^{\text {EGFL7 }}$ had no effect. MSCs ${ }^{\text {sonic hedgehog }}$ even increased lesion size compared to MSCs. At this time point, although MSCs ${ }^{\mathrm{BDNF}}$ elevated number of BrdU-positive cells in the hippocampus, cell therapy did not affect the number of Ki67 positive cells.

To evaluate the therapeutic effects of the BDNF or/and noggin-modified BM-MSCs, Lu et al. [89] intravenously administered stem cells one day after $60 \mathrm{~min}$ MCAO. One week after transplantation, transplanted stem cells improved mNSS, and genetically modified stem cells enhanced functional improvements. The recovery was even amplified in the group co- transfected with BDNF and noggin. Western blot and immunohistochemistry analysis in the ipsilateral cerebral cortex showed that modified MSCs increased the expression of VEGF, Bcl-2, p-GSK3 $\beta$, and p-Akt, but decreased Bax, TLR4, and MyD88 compared to non-transplanted control and MSCs groups. Also, an ELISA assay revealed transplanted stem cells reduced levels of matrix metallopeptidase 9 as well as reactive oxygen species and co-transfected MSCs ${ }^{\text {BDNF-noggin }}$ had the most powerful effect to decrease these factors.

Altogether, these data suggest that the delivery of BDNF by ex vivo gene transfer, using mesenchymal or neural stem cells, potentiated therapeutic effects of naive stem cells in mouse or rat models of cerebral ischemia. The obtained results indicate that the combination of gene and cellular therapy by over-expressing BDNF in the transplanted stem cells, led to enhanced neurogenesis and promoted stem cell proliferation, protected cells from apoptotic death as well as ameliorated behavioral dysfunction more effectively and rapidly than non-transfected stem cells.

\section{Neurotrophin-3 (NT-3)}

NT-3 is a member of the neurotrophin family that could promote survival of nearly all types of neurons and is involved in differentiation promoting pathways [90]. It was reported that NT-3 elevates the differentiation potential of stem cells toward neurons [91-93], and NT-3 knockout mice showed impaired neurogenesis [94]. In addition, NT-3 was able to stimulate neovascularization in a limb model of ischemia, which was induced by surgically excising the femoral artery [95].

Park and co-workers [47] evaluated the effects of mouse NSCs over-expressing NT3 in hypoxic-ischemic brain injury. Hypoxic-ischemic injury in 7-day old mice was induced by right common carotid artery occlusion, followed by 2-3 h exposure to $8 \% \mathrm{O} 2$ and $92 \% \mathrm{~N} 2$. Stem cells were transplanted 3 days later in two sites at the ipsilateral infarcted hemisphere, which were 1-1.5 mm apart, or the contralateral lateral ventricle. Immunostainings of the brain slices 2-4 weeks after implantation showed $\mathrm{NSCs}^{\mathrm{NT} 3}$ differentiated into neurons at a higher rate in infarct cavity $(20 \%)$ and penumbra $(81 \%)$ than NSCs alone $(5 \%)$. Small portion of $\mathrm{NSCs}^{\mathrm{NT3}}$ expressed oligodendroglial $(0.4 \%)$ and astroglial markers $(1 \%)$. A subpopulation of $\mathrm{NSCs}^{\mathrm{NT} 3}$ derived neurons were either cholinergic (25-40\%), glutamatergic (10-20\%) or GABAergic (40-50\%).

Furthermore, Zhang et al. [48] transplanted NSCs overexpressing human NT3 into the striatum ipsilateral to the injury of adult rats, 7 days after $2 \mathrm{~h}$ MCAO. The rats that received stem cells exhibited enhanced functional recovery in neurological and behavioral tests, 7 and 14 days after transplantation. The neurological severity score of rats in both modified and non-modified stem cells groups were similar 
within seven days after implantation. However, animals that received NSCs ${ }^{\text {hNT3 }}$ displayed a better functional performance than animals transplanted with wild type NSCs, fourteen days after transplantation.

Taken together, the evaluated studies revealed that NT-3 over-expressing exogenous neural stem cells are able to improve functional recovery following brain ischemia. In addition, over-expressed NT-3 has a potential to promote neuronal differentiation.

\section{Over-expression of Glial-derived Neurotrophic Factor (GDNF)}

GDNF belongs to the transforming growth factor beta family, which is able to promote survival of several types of central and peripheral neurons. Previous studies have shown that intracerebroventricular and intracortical [96] or intrastriatal [97] administration of GDNF resulted in protection of cerebral hemispheres from damage and neuroregenerative responses.

Kurozumi and colleagues [49] compared therapeutic effects of human BM-MSCs over-expressing BDNF, GDNF, NT3 and ciliary neurotrophic factor (CNTF) in a rat model of cerebral ischemia, induced by 90 min MCAO. Stem cells transplanted into ipsilateral striatum one day after stroke. At day 8 and 15 after MCAO, rats that received MSCs ${ }^{\text {GDNF }}$ achieved higher limb placement scores compared to control. Similarly, MSCs ${ }^{\text {GDNF }}$ could reduce infarct area 7 and 14 days after ischemia. In addition, discosoma red fluorescent protein- positive MSCs were more numerous in the injection site of animals treated with $\mathrm{MSCs}^{\mathrm{GDNF}}$ than MSCs group, 14 days after MCAO.

Horita et al. [50] investigated whether hMSCs overexpressing GDNF could contribute to functional recovery in a rat pMCAO model. The pMCAO was induced by intraluminal vascular occlusion and $\beta$-galactosidase (LacZ) transfected hMSCs ${ }^{\text {GDNF }}$ were intravenously administered three hours later. The $\beta$-galactosidase positive $\mathrm{hMSCs}{ }^{\mathrm{GDNF}}$ were detected throughout the injured hemisphere mainly in the penumbra lesion, one week after cell therapy. An estimate of infarct volume was obtained using in vivo diffusion-weighted (see Box 1) and T2-weighted magnetic resonance imaging. Based on the diffusion-weighted imaging, stem cells curative effects to reduce infarct size were detected only in the first week after transplantation. However, on T2W imaging, infarct size was decreased in stem cell transplanted groups in all evaluated time points from day 1 up to day 28 after stroke and hMSCs ${ }^{\mathrm{GDNF}}$ had better outcome at all time points to reduce infarct area. Also, intravenous delivery of hMSCs ${ }^{\text {GDNF }}$ led to reduction in lesion size, as estimated from TTC staining 1 week after MCAO. By using the treadmill stress test, stem cell transplanted groups showed improvement in treadmill velocity up to 31 days. Again, hMSCs ${ }^{\text {GDNF }}$ had better outcome in all evaluated time points.

In addition, Chen and colleagues [51] transplanted rat NSCs transfected with GDNF into the ipsilateral lateral ventricle, three days after $120 \mathrm{~min}$ MCAO. Stem cell transplantation led to decreased neurological severity scores from week 1 to 7 compared to non-transplanted control group. NSCs ${ }^{\mathrm{GDNF}}$ only at weeks 2 and 3 showed behavioral improvements, compared to naive NSCs. Stem cells reduced infarct volume from week 1 up to week 7 compared to control; NSCs ${ }^{\text {GDNF }}$ only at week 1 had better results compared to NSCs. Also, more GFP and BrdU positive stem cells were detected in the NSCs ${ }^{\text {GDNF }}$ group, compared to NSCs up to 7 weeks after stroke. Cell therapy and more specifically NSCs ${ }^{\text {GDNF }}$ enhanced synaptophysin and PSD-95 immunoreactivity whereas decreased number of caspase- 3 and TUNEL positive cells in all evaluated time points. Elevated expression of synaptic proteins could suggest the reconstruction of neural circuitries and/or enhanced neuronal functioning following stem cell grafting.

$\mathrm{Ou}$ and co-workers [52] evaluated the therapeutic effects of human umbilical cord blood (HUCB) CD34 + cells over-expressing GDNF, in spontaneous hypertensive rats exposed to $120 \mathrm{~min}$ MCAO. At $6 \mathrm{~h}$ after stroke, stem cells were administered into the tail vein. Cell therapy reduced infarct size 7 days after transplantation and UCBCs ${ }^{\text {GDNF }}$ had greater outcome compared to UCBCs. GDNF over-expression increased survival of GFP positive stem cells compared to NSCs in the injured hemisphere. Double immunostaining against GFP and GFAP on day 28 showed more than $75 \%$ of the total cells were GFP-GFAP suggesting glial preferential differentiation of transplanted cell. Stem cells improved mNSS scores on days 7 and 28 and $\mathrm{UCBCs}^{\mathrm{GDNF}}$ enhanced behavioral improvements compared to UCBCs.

Wang et al. [53] evaluated the therapeutic effect of transplanted GDNF modified rat BM-MSCs on an experimental ischemic brain injury. The stem cells were injected three days after $120 \mathrm{~min}$ MCAO via the caudal veins. The animals were evaluated at 3,14 , and 28 days after transplantation. At all time points, animals that underwent cell therapy showed behavioral improvements, which was obtained from ipsilateral circling, bilateral grasp and beam walking tests. At days 14 and 28, GDNF modified MSCs enhanced behavioral improvements compared to non-transfected MSCs. Also stem cells reduced TUNEL positive apoptotic cells as well as increased Bcl-2 positive cells around the ischemic region in evaluated time points and $\mathrm{MSCs}^{\mathrm{GDNF}}$ group showed enhanced outcome compared to MSCs.

Overall, grafting bone-marrow mesenchymal or neural stem cells with a modified GDNF gene can ameliorate 
devastating conditions following stroke. It has been proposed that the cellular delivery of GDNF-secreting-stem cells could promote survival and migration of transplanted cells, improve the local microenvironment and accelerate nervous function recovery.

\section{Over-expression of Angiogenic Factors}

\section{Vascular Endothelial Growth Factor (VEGF)}

VEGF has been involved in all aspects of vascular formation including vasculogenesis, angiogenesis and arteriogenesis. In addition, VEGF has neuroprotective effects; therefore it is considered as one of the key elements in stroke [98]. It was reported that intracerebroventricular administration of VEGF peptide after cerebral ischemia in mice and rats led to angiogenesis stimulation, neurological performance improvement, infarct size reduction and enhanced newborn neurons survival in the subventricular zone and dentate gyrus $[99,100]$.

Considering evidence of functional recovery in stroke animal models following stem cell transplantation as well as VEGF treatment, Miki et al. [54] prepared gene-modified rat BM-MSCs that strongly expressed human VEGF. Stem cells were transplanted intracerebrally $24 \mathrm{~h}$ after $120 \mathrm{~min}$ MCAO. Between 14 and 28 days after stroke, the rats treated with MSCs or MSCs ${ }^{\text {VEGF }}$ showed mNSS improvement compared to control. In addition, the MSCs ${ }^{\mathrm{VEGF}}$ showed remarkable functional recovery compared to the non-transfected MSCs. On day 14 after ischemia, the infarct size assessed by TTC staining decreased in the stem cell transplanted groups and rats receiving MSCs ${ }^{\mathrm{VEGF}}$ showed more reduction than native MSCs group. Brain water content was also measured 2 and 7 days after stroke and no significant difference was detected among the experimental groups at either analysis point.

In another study, Lee and co-workers [55] induced intracerebral hemorrhage by the administration of collagenase type IV into the striatum of mice (gender was not defined). Seven days later, immortalized cell lines of human neural stem cells (HB1.F3), over-expressing VEGF were transplanted into the ipsilateral striatum. Stem cell transplantations led to a functional improvement in rotarod and modified limb placement tests from eight days post-implantation and the curative effects lasted for up to eight weeks. Enhanced behavioral recovery in $\mathrm{NSCs}^{\mathrm{VEGF}}$ vs. NSCs groups were observed 3 to 9 weeks after grafting. VEGF over-expression led to a two-fold increase in cell survival of implanted NSCs at two weeks postadministration and a three-fold increase at eight weeks after implantation. The majority of grafted NSCs ${ }^{\mathrm{VEGF}}$ cells differentiated into either astrocytes $(55-65 \%)$ or neurons (35$45 \%)$. NSCs ${ }^{\mathrm{VEGF}}$ promoted proliferation of host endothelial cells/microvessels compared to the non-transfected NSCs at two- and eight-weeks post-grafting. The number of TUNELpositive apoptotic cells in the hemorrhage core border areas, was lower in the stem cell transplanted groups eight weeks after implantation. Western blot analysis revealed increased expression of proapoptotic proteins Bax and caspase 3 in the control group; however, marked reduction of these proteins was detected in the stem cell transplanted groups. On the other hand, the levels of survival signal molecules Akt1, p110 and p58 as well as anti-apoptotic proteins Bcl-XL and Bcl-2 were higher in the stem cell grafted groups.

In summary, stem cells that over-express VEGF exert neuroprotective effects in the ischemic brain, by promoting antiapoptotic and/or inhibiting pro-apoptotic elements. Also, stem cells transfected with VEGF rejuvenated angiogenesis of host brain tissue and enhanced its functional recovery.

\section{Angiopoietin}

Angiopoietin belongs to the vascular growth factors family that plays a role in remodeling, stabilization and maturation of vessels. Angiopoietin-1 (Ang1) is the well-known member of this family and binds to Tie2, a receptor tyrosine kinase. Tie2 is expressed in the choroid plexus as well as on endothelial cells lining blood vessels which induces neovascularization in the brain [101].

In a study conducted by Onda and co-workers [56], human BM-MSCs had been transfected with the Ang-1 gene and were intravenously administered $6 \mathrm{~h}$ after induction of unilateral permanent cerebral ischemia in rats. At 1, 3, and 7 days after pMCAO, MRI-estimated infarct size was less in both $\mathrm{MSC}$ and $\mathrm{MSCs}^{\text {Ang }}$ groups without any significant differences between them. Similar results were obtained by TTC staining 7 days after pMCAO. Stem cell therapy increased capillary vascular volume ratio (ipsilateral/contralateral) at 7 and 28 days after pMCAO. The vascular volume ratio of $\mathrm{MSCs}^{\mathrm{Ang}}$ treated group was higher than MSCs group in both time points. In addition, stem cell transplantation led to increased regional cerebral blood flow in some regions up to 7 days post-MCAO. From 1 to 7 days after transplantation, both MSCs and $\mathrm{MSCs}^{\text {Ang }}$ groups had greater maximum velocity on a motor-driven treadmill than control, but the MSCs ${ }^{\text {Ang }}$ group attained a higher velocity than the non-transfected MSCs.

Toyama and colleagues [57] investigated whether the combination of Ang1 and VEGF gene-modified human BMMSCs contribute to functional recovery in a rat model of pMCAO. Stem cells were intravenously administered $6 \mathrm{~h}$ after occlusion. To evaluate the relative efficacy of MSCs, $\mathrm{MSCs}^{\mathrm{Ang}}, \mathrm{MSCs}^{\mathrm{VEGF}}$ and MSCs ${ }^{\mathrm{Ang}-\mathrm{VEGF}}$ transplantation, infarct volume was estimated using in vivo MRI analysis. At 1 , 3, 7 and 14 days, infarct size reduced in the MSCs, MSCs ${ }^{\text {Ang }}$ and MSCs ${ }^{\text {Ang-VEGF }}$ groups; however, infarct area tended to increase in the MSCs ${ }^{\text {VEGF }}$ group. The reduction was not significant between MSCs and MSCs ${ }^{\text {Ang }}$, but it was statistically 
significant between MSCs ${ }^{\text {Ang-VEGF }}$ and other groups. Similar results were obtained by TTC staining at day 7 . Based on the three-dimensional capillary imaging obtained from systemically perfused fluorescein isothiocyanate-dextran 7 days after MCAO, stem cells led to higher capillary vascular volume ratio and MSCs ${ }^{\text {Ang-VEGF }}$ treated group showed higher ratios than others. Also, stem cells except MSCs ${ }^{\mathrm{VEGF}}$ led to increased regional cerebral blood flow in some regions 7 days post transplantation. The treadmill stress test showed that the maximum speed at which the rats could run on a motor driven treadmill was faster in MSCs, MSCs ${ }^{\text {Ang }}$ and $\mathrm{MSCs}^{\mathrm{Ang}}$ -VEGF treated rats from 1 up to 14 days post-MCAO. The MSCs ${ }^{\mathrm{VEGF}}$ even reduced maximum velocity compared to the control at day 14 .

Together, although human bone-marrow mesenchymal stem cells over-expressing angiopoietin modestly improved angiogenesis and functional recovery, co-transfection of angiogenic factors e.g. angiopoietin and VEGF are likely to improve cerebral ischemia therapies.

\section{Placental Growth Factor (PIGF)}

The angiogenic factor, PlGF, belongs to the VEGFs gene family, and has a $53 \%$ homology to VEGF. PIGF has a crucial role in the placental chorion angiopoiesis and maintenance of the placenta development and normal growth. PIGF is also expressed in the CNS and plays a role in cerebral ischemic injury [98]. In this regard, the neuroprotective properties of PIGF have been reported in an in vitro model of ischemic condition [102], and PlGF-knockout mice showed a deficit in hypoxia-induced cerebral angiogenesis [103].

In the Liu et al. [58] study, PlGF modified human BM-MSCs were intravenously administered $3 \mathrm{~h}$ after induction of unilateral pMCAO in a rat. An estimated infarct size obtained by in vivo MRI revealed that, although lesion volumes $3 \mathrm{~h}$ after occlusion were the same among the experimental groups, infarct size was smaller $6 \mathrm{~h}$ after MCAO in the MSCs ${ }^{\text {PIGF }}$ group. At 1, 3, 4 and 7 days, infarct size was smaller in both MSCs and MSCs ${ }^{\text {PlGF }}$ groups compared to control. The reduction in infarct volume was greater in MSCs ${ }^{\mathrm{PIGF}}$ compared to MSCs at 3, 4, and 7 days post-occlusion. Similar results were also obtained by TTC staining at day 7. Three-dimensional analysis of capillary vessels in the lesion site 7 days after MCAO showed the capillary vascular volume ratio was higher in stem cells treated group and the angiogenesis was greater in the MSCs ${ }^{\mathrm{PIGF}}$. This trend was also observed in the number of apoptotic cells; fewer TUNELpositive cells were found in rats receiving MSC ${ }^{\mathrm{PIGF}}$ than those in MSC and control groups. Based on the limb placement and treadmill stress behavioral tests, MSCs ${ }^{\text {PIGF }}$ and MSCs improved functional recovery from day 1 and day 3 respectively up to day 7 after transplantation. Therefore, over-expression of PIGF might enhance angiogenesis and neuroprotection properties of mesenchymal stem cells in cerebral ischemia.

\section{Hypoxia-inducible Factor 1 (HIF-1)}

HIF-1 is a master regulator of hypoxia-responsive genes. The expression of a wide variety of genes that facilitate adaptation to low $\mathrm{O} 2$ levels is regulated by HIF-1. It targets different molecules with vast range of functions, including energy metabolism, cell proliferation, erythropoiesis, angiogenesis and vasomotor control. All of these genes may potentially contribute to the recovery of neuronal cells following cerebral ischemia and reperfusion. Due to potential key roles of genes modulated by ischemia-activated HIF-1, it has been proposed that modulating induction and accumulation of HIF-1 is a curative strategy for cerebral ischemia. HIF-1 as a heterodimeric transcription factor contains two subunits of HIF- $1 \alpha$ and HIF-1 $\beta$. HIF- $1 \alpha$ protein synthesizes and degrades continuously, therefore it is almost absent in normoxic cells. On the other hand, HIF- $1 \beta$ does not response to $\mathrm{O} 2$ levels and is constitutively expressed in cells; however it is necessary for hypoxiainduced transcriptional changes mediated by HIF-1. Hence, activation of HIF-1 mainly depends on the HIF- $1 \alpha$ protein level [104, 105].

In this regard, $\mathrm{Wu}$ and colleagues [59] investigated the efficacy of HIF- $1 \alpha$ modified NSCs in a rat model of stroke induced by a 90 min MCAO. BrdU-labelled stem cells were transplanted one day after MCAO into the lateral ventricle. From day 7 up to day 28 post ischemia, animals receiving $\mathrm{NSCs}^{\mathrm{HIFla}}$ scored better in mNSS than other groups. At days 21 and 28, NSCs group also showed greater functional recovery compared to control. The numbers of BrdU-positive cells in the infarct area were greater in NSCs ${ }^{\mathrm{HIFla}}$ than NSCs that could differentiate into both neuronal and glial cells. Also, $\mathrm{NSCs}^{\mathrm{HIF} 1 \mathrm{a}}$ increased factor VIII-positive endothelial cells at the lesion sites at day 35 after MCAO.

Ye et al. [60] injected HIF1 $\alpha$ over-expressing BM-MSCs into rat tail vein $3 \mathrm{~h}$ after permanent MCAO. Rats treated with $\mathrm{MSCs}^{\mathrm{HIF} \text { 1a }}$ had functional improvement on mNSS from day 7 post-MCAO compared to control. MSCs showed neurological functional recovery compared to control from 14 days after ischemia. MSCs ${ }^{\mathrm{HIFla}}$ led to better outcome on days 14 and 28. Based on the Morris Water Maze test (see Box 2), stem cells transplantations decreased latency periods and travel distances compared to control at both days 14 and 28 post MCAO without significant difference between transfected and nontransfected MSCs. Just MSCs ${ }^{\mathrm{HIFla}}$ had a potential to reduce infarct volume at day 7. Tracking of GFP-labelled transplanted MSCs showed the presence of stem cells in the olfactory area at day 1 , in the boundary area of the injured cortex, mainly including hypothalamus, thalamus, internal ventricle at day 7 and in the striatum and motor cortex fields adjacent to the infarct region at day 14. Although stem cell administration did not affect the number of apoptotic cells in the cortex, $\mathrm{MSCs}^{\mathrm{HIF} 1 \mathrm{a}}$ reduced apoptosis in the hippocampus compared to control at day 7 after MCAO. Double 
immunofluorescent staining in the hippocampus region at day 7 and cortex at day 14 post MACO revealed increased number of pax6/DCX cells in the MSCs ${ }^{\mathrm{HIF} 1 \mathrm{a}}$ group, indicating enhanced neuronal proliferation.

Yang and co-workers [61] injected BM-MSCs over-expressing HIF $1 \alpha$ into the rat tail vein $6 \mathrm{~h}$ after $120 \mathrm{~min}$ MCAO. Only MSCs ${ }^{\mathrm{HIF} 1 \alpha}$ improved the mNSS score from days 14 to 28 and reduced infarct size at days 14 and 28 . Western blot analysis showed that MSCs ${ }^{\mathrm{HIF} 1 \alpha}$ elevated VEGF protein expression in the injured hemisphere. Angiogenesis detected by CD105 staining in the MSCs group showed a small amount of scattered microvascularization at day 7 after stroke; the revascularization reached a maximum on day 14 and decreased gradually afterward. In the MSCs ${ }^{\mathrm{HIF} 1 \alpha}$ group, density of neomicrovascular vessels was denser at day 7 , reached its maximum on day 14 and kept at a relatively high level until day 28 .

Ye et al. [62] evaluated the therapeutic effects of NSCs over-expressing HIF $1 \alpha$ in a rat model of stroke induced by 90 min MCAO. Stem cells were injected into cortical periinfarct regions of the rat brain at $24 \mathrm{~h}$ after MCAO. NSCs ${ }^{\mathrm{HIF} 1 \alpha}$ treatment showed an improvement in NSS scores compared to control on days 7, 14, 21 and 28 post ischemia. NSCs treatment had a significant functional recovery compared to control on days 21 and 28 ; however, NSCs ${ }^{\mathrm{HIF} 1 \alpha}$ had better outcome at these time points. Nissl staining (see Box 1) 5 weeks after ischemia showed that cortical and hemispheric atrophy of the lesion sites was reduced in the $\mathrm{NSCs}^{\mathrm{HIF} 1 \alpha}$ group. Also, the number of BrdU labelled transplanted stem cells in the peri-ischemic area was higher in the genetically modified group, 35 days after MCAO. Double staining against BrdU/ NF-200 and BrdU/GFAP showed that transplanted NSCs could differentiate into neuronal and glial cells at day 35 . Number of VEGF and vWF positive cells were also increased in the peri-ischemic area in the NSCs ${ }^{\mathrm{HIF} 1 \alpha}$ compared to control, 7 and 35 days after ischemia, respectively.

Lin et al. [63] aimed to evaluate therapeutic efficiency of rat BM-MSCs over-expressing HIF- $1 \alpha$ in hypoxic-ischemic brain damage. Hypoxic-ischemic injury in rats was induced by left common carotid artery occlusion followed by $2 \mathrm{~h}$ exposure to $8 \% \mathrm{O} 2$ and $92 \% \mathrm{~N} 2$. chloromethylbenzamido dialkylcarbocyanine (CM-DiI) labelled stem cells intravenously injected into the tail $24 \mathrm{~h}$ after ischemia. Tracking of CM-DiI labelled stem cells showed the presence of positive cells in the hippocampus on day 7 after ischemia. From day 7 to day 21 after ischemia, the number of CM-DiI positive cells in the hippocampus elevated gradually in a time-dependent manner. Over-expression of HIF-1a enhanced the migration potential of MSCs toward the injury sites. The spatial performance was assessed by Morris Water Maze on day 14 after ischemia. There was an increase of time in the target quadrant in stem cell transplanted groups compared to control, however, a higher increase in the amount of time have been found in MSCs ${ }^{\mathrm{HIF} \text { la }}$ group. Furthermore, hematoxylin and eosin staining (see Box 1) of the hippocampus showed that stem cells were able to ameliorate pathological changes that occurred after ischemia, whereas MSCs ${ }^{\mathrm{HIF} 1 \alpha}$ enhanced therapeutic efficiency.

Collectively, these data support the hypothesis that transfection of bone-marrow mesenchymal stem cells or neural stem cells that over-express hypoxia-inducible factor 1, could protect the vascular system and grafted stem cell survival, increase migration of stem cells to the infarct area, stimulate angiogenesis as well as neurogenesis, and enhance motor function in cerebral ischemia models.

\section{Over-expression of Trophic Factors}

\section{Fibroblast Growth Factor (FGF)}

The fibroblast growth factors (FGFs) are a family of cell signaling proteins that participate in a broad range of processes, especially as pivotal factors for normal development. FGFs are also crucial for the adult brain maintenance. Hence, FGFs are one of the main elements involved in neuronal survival and synaptic plasticity during both development and adulthood [106]. Previous studies reported that exogenous FGF can reduce infarct size area in acute stroke (3-6 h after stroke) and enhance neurological recovery in chronic stroke (72-168 h after stroke) [107].

Ikeda and colleagues [64] evaluated the effect of FGF-2 modified BM-MSC in a rat ischemic stroke model. Stem cells administered stereotaxically in the striatum $24 \mathrm{~h}$ after $2 \mathrm{~h}$ MCAO. Seven days post MCAO, the rats treated with $\mathrm{MSC}^{\mathrm{FGF} 2}$ showed improvements in the mNSS score, compared to control. At 14 and 21 days after cerebral ischemia, functional improvements were also found in the MSC group compared to control; however, $\mathrm{MSC}^{\mathrm{FGF} 2}$ had a better outcome at both time points. Just MSC ${ }^{\text {FGF2 }}$ decreased infarct volume, 14 days after MCAO.

Ghazavi et al. [65] evaluated the effect of an acute intravenous injection of adipose-derived mesenchymal stem cells transfected with the $F g f l$ gene, $30 \mathrm{~min}$ after $30 \mathrm{~min}$ MCAO. The main outcomes of this study were assessed $24 \mathrm{~h}$ post MCAO. Stem cell transplanted groups showed a functional improvement, as assessed by rotarod and Roger's tests and reduced apoptotic cells stained by TUNEL. For both parameters, $\mathrm{MSC}^{\mathrm{FGF} 1}$ had better outcome than MSC. Also, based on TTC data, stem cells reduced lesion volume and there was no significant difference between stem cell transplanted groups.

Zhang et al. [66] evaluated the effects of intravenous administration of FGF2 modified NSCs (C17.2 cell line) in a rat model of stroke. Stem cells were transplanted $24 \mathrm{~h}$ after $2 \mathrm{~h}$ MCAO. To determine the proliferation potential of administered NSCs in the injured area, animals received BrdU after anesthesia via tail vein on the day of implantation and every 
day, for 28 days. Behavioral performance showed a remarkable advance in neurological severity scores from 7 days post$\mathrm{MCAO}$ in $\mathrm{NSCs}^{\mathrm{FGF} 2}$ and 14 days post-MCAO in NSCs groups up to 28 days after transplantation. However, no significant differences were observed in the infarct size among experimental groups compared to control. Using pre-labeled cells with CMDiI, red fluorescent dye, it has been found that FGF2 promoted the migration of NSCs into the injured brain and increased the survival of cells in the infarcted area at day 28. Also, at this time point, around $45 \%$ of the transplanted $\mathrm{NSCs}^{\mathrm{FGF} 2}$ and $30 \%$ of the NSCs overlapped with BrdU staining. Furthermore, $\mathrm{NSCS}^{\mathrm{FGF} 2}$ elevated the NeuN-positive cells co-localization with CM-DiI, in comparison to the NSCs. The number of GFAP immunoreactive cells co-localized with CM-DiI cells was not significantly different between the two groups. Nestin colocalization with CM-DiI cells was reduced in the $\mathrm{NSCs}^{\mathrm{FGF} 2}$ group, compared to the NSCs group. Hence, it seems that FGF2 accelerated differentiation of NSCs into mature neurons.

Taken together, over-expression of the fibroblast growth factor might be one approach to improve the restorative potential of stem cells, in order to accelerate functional recovery after stroke.

\section{Hepatocyte Growth Factor (HGF)}

HGF is a potent pleiotropic cytokine that is involved in angiogenesis, morphogenesis, mitogenesis, tissue regeneration, and anti-apoptosis in various cell types. Exogenous HGF has been reported to improve the neurological sequelae by decreasing the infarct area size after stroke [108].

Zhao and co-workers [67] evaluated the effects of BMMSCs overexpressing HGF, which were intrastriatally implanted in the superacute $(2 \mathrm{~h})$ and acute $(24 \mathrm{~h})$ phase of rat MCAO model. Superacute MSCs ${ }^{\mathrm{HGF}}$ transplantation led to better mNSS from day 4 post-ischemia; however, MSCs improved the behavioral function from day 14 and these effects continued until day 35 . Beneficial effects of stem cells that improved neurological deficits after acute transplantation were observed at day 7 and 14 in $\mathrm{MSCs}^{\mathrm{HGF}}$ transplanted rats, and at day 14 in MSCs group. Three days after superacute transplantation of stem cells, the infarct volume was reduced just in the MSCs ${ }^{\mathrm{HGF}}$ transplanted rats compared to control; acute administration did not affect infarct area size at this time point. Superacute transplantation of stem cells led to reduced infarct size on day 14 ; however, by acute administration, infarct volume was reduced in the MSCs ${ }^{\mathrm{HGF}}$ compared to MSCs or control groups. On day 7, the ischemic boundary zone showed a significantly reduced percentage of apoptotic cells in the $\mathrm{MSCs}^{\mathrm{HFG}}$ treated group compared to other groups. The result was the same when the MSC group was compared to non-transplanted control. Hence, MSCs ${ }^{\mathrm{HFG}}$ therapy in the superacute phase of stroke might be more therapeutically efficient than MSC alone.

\section{Pigment Epithelium-derived Factor (PEDF)}

PEDF is a broadly expressed multifunctional member of the serine proteinase inhibitor (serpin) family. This broadly investigated protein plays key roles in a variety of pathophysiological and physiological processes such as inflammation, fibrogenesis, angiogenesis and neuroprotection.

Huang et al. [68] investigated the protective effect of exosomes isolated from PEDF over-expressing adipose derived stem cells in the rat cerebral ischemia-reperfusion injury model. Daily administration of exosomes through the lateral cerebral ventricle was started 3 days before MCAO. Three days after reperfusion, PEDF-exosome reduced the infarct volume, decreased relative apoptosis rate and prevented MCAO-induced apoptotic pathway activation through reducing cleaved/total caspase-3 as well as cleaved/total caspase- 9 . Thus, pre-treatment with exosomes obtained from PEDFmodified adipose stem cells, could ameliorate cerebral ischemia by modulating apoptosis and autophagy.

\section{Over-expression of Genes Involved in Cell Survival and/or Migration}

\section{AKt1}

A serine/threonine kinase, Akt, plays a crucial role in the regulation of cell survival, growth and proliferation. Aktl protein is known as a general mediator of cell survival signals in the NSCs. Lee and colleagues reported that grafted human NSCs had low survival rates in ischemia and ICH mice; with less than $50 \%$ of transplanted NSCs survived in ICH at 2-weeks post grafting and $30 \%$ at 8 -weeks $[55,109]$. Therefore, it was hypothesized that implanting NSCs that overexpress Aktl into the damaged area could improve the viability of hNSCs.

Lee et al. [69] induced ICH by intrastriatal administration of bacterial collagenase type IV and seven days later, human NSCs (HB1.F3), overexpressing Akt1 were transplanted into ipsilateral striatum of mice. Stem cell transplantation resulted in an improved behavioral performance based on the rotarod and limb placement test from 2 up to 8 weeks post transplantation without significant difference between NSCs and $\mathrm{NSCs}^{\mathrm{Akt1}}$. Eight weeks after cell therapy, around 35-54\% transplanted NSCs ${ }^{\text {Akt1 }}$ differentiated to NF-H positive neurons; however just around $4 \%$ of them were GFAP positive astrocytes. Immunostaining against human nuclear matrix antigen (hNuMA) showed that Akt1 overexpression resulted in a $40 \%$ increase in cell survival of transplanted NSCs at 2 weeks post-transplantation and $100 \%$ increase at 8 weeks posttransplantation in the hemorrhage core border areas. Also, $\mathrm{NSCs}^{\text {Akt1 }}$ were able to migrate to the hippocampus at week 8. Transplanted NSCs or NSCs ${ }^{\text {Akt1 }}$ were immuno-negative for the cell proliferation marker Ki-67, indicating that grafted 
stem cells did not continue to proliferate following transplantation. Furthermore, hematoxylin and eosin-stained sections of mouse brains transplanted with NSCs or $\mathrm{NSCs}^{\mathrm{Akt1}}$ six months post-transplantation showed no sign of tissue distortion or tumor formation. Accordingly, overexpression of Akt1 might enhance the survival of grafted neural stem cells in the ischemic brain.

\section{B-cell Lymphoma 2 (Bcl2)}

$\mathrm{Bcl}-2$ is the founding member of the Bcl-2 family of regulator proteins that regulate cell death by either inducing or inhibiting apoptosis. Wei et al. [70] evaluated the therapeutic effects of mouse embryonic stem cells (ESCs) overexpressing $\mathrm{Bcl} 2$ in a rat stroke model induced by $120 \mathrm{~min}$ MCAO. BrdU-labelled stem cells were transplanted seven days after MCAO into 4 cerebral regions (Fig. 3).

TUNEL staining 3 days after transplantation revealed fewer cell death in $\mathrm{ESCs}^{\mathrm{Bcl} 2}$ compared to ESCs group in the ischemic core region. Fourteen days after cell therapy, the number of neuron-like NeuN positive transplanted ESCs or $\mathrm{ESCs}^{\mathrm{Bcl} 2}$ were $34 \pm 11 \%$ and $58 \pm 7 \%$, respectively. Also, some transplanted cells in the post-ischemic cortex and striatum stained positively for GFAP (astrocyte marker), neural/ glial antigen-2 (NG-2, oligodendrocyte precursor marker) and adenomatous polyposis coli (APC, mature oligodendrocyte marker). Seven weeks after transplantation, the formation of neural structures was detected by NF staining and possible neovascularization was detected by Glut-1, a marker for differentiated endothelial cells. Stem cell transplantations led to better neurological severity scores from day 7 to 35 . After 21 days of transplantation, animals transplanted with $\mathrm{ESCs}^{\mathrm{Bcl} 2}$ showed an enhanced neurological recovery rate than animals transplanted with ESCs.

Fig. 3 Wei et al. [70] transplanted embryonic stem cells into 4 different coordinates
In another study, Korshunova et al. [71] compared survival, differentiation potential, as well as therapeutic effects of transplanted human NSCs (H9 cells) over-expressing Bcl2, Bcl-xl, Akt1, HIF-1 $\alpha$ and Bcl $2+\mathrm{Bcl}-\mathrm{xl}+\mathrm{Akt1}$ in a mouse model of permanent focal cerebral ischemia. Stem cells implanted two days after permanent MCAO and their survival was evaluated one week as well as 1,2 and 3 months after transplantation. Although more than $93 \%$ of naive implanted stem cells died in the first week, around $30 \%$ of $\mathrm{NSCs}^{\mathrm{Akt1}}$ and $20 \%$ of $\mathrm{NSCs}^{\mathrm{Bcl} 2}, \mathrm{NSCs}^{\mathrm{Bcl}-\mathrm{xl}}$ and $\mathrm{NSCs}^{\mathrm{HIF} 1 \alpha}$ survived at this time point. The number of survived naïve transplanted NSCs declined to $1.8 \%$ of initial implantation after three months; however, over-expression of Akt1, Bcl2 or Bcl-xl, preserved the number of survived stem cells to around $20 \%$ at month three. NSCs ${ }^{\mathrm{Akt1}+\mathrm{Bcl} 2+\mathrm{Bcl}-\mathrm{xl}}$ had survival effects similar to $\mathrm{NSCs}^{\mathrm{Akt1}}$, indicating a similar signaling pathway for all three factors. For further confirmation, the authors showed that five days after implantation many naïve stem cells expressed the apoptotic marker activated caspase-3; however, there was no activated caspase- 3 and EGFP co-expressing cells in engineered cells. Three months after transplantation, all engineered stem cells, except NSCs ${ }^{\mathrm{HIF} 1 \alpha}$, expressed nestin as indicator for neural precursor cells. At this time point, around $15 \%$ of transplanted $\mathrm{NSCs}^{\mathrm{Bcl}-\mathrm{xl}}$ expressed $\mathrm{NeuN}$ as mature neuron marker, and none of the engineered stem cells differentiated into GFAP positive astrocytes. Eventually, the authors evaluated the motor function of treated mice, seven days after implantation. $\mathrm{NSCs}^{\mathrm{Bcl}-\mathrm{xl}}$ transplantation led to a significant functional improvement, compared to nontransplanted and NSCs groups, based on the latency-to-move, sticky-tape-removal, and Collins tests.

Therefore, over-expression of $\mathrm{Bcl}-2 / \mathrm{Bcl}-\mathrm{xl}$ is able to promote the survival of transplanted embryonic/neural stem cells, increase neuronal differentiation, and improve functional outcome.

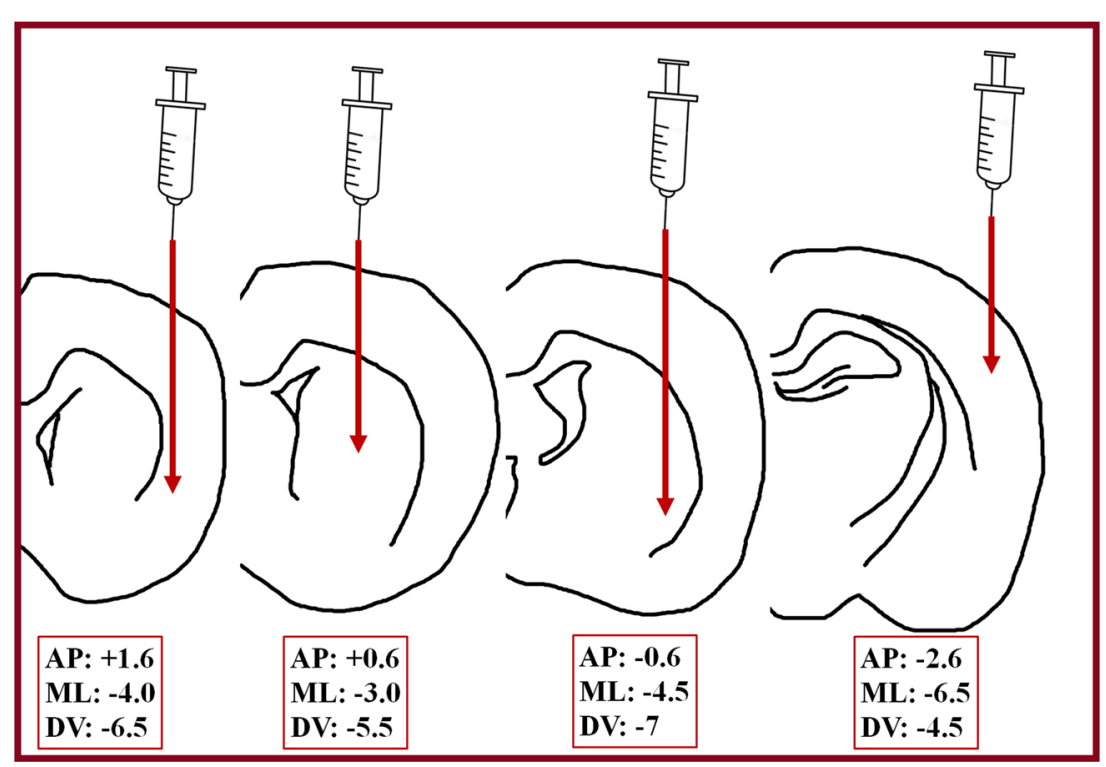




\section{C-X-C Chemokine Receptor Type 4 (CXCR-4)}

SDF1 (stromal cell-derived factor 1), also known as CXCL12 (C-X-C motif chemokine 12), belongs to the CXC subfamily of chemokines. SDF1 is considered to preserve adult and embryonic NSCs and being involved in the recruitment of NSCs to damaged regions to enhance recovery [110]. Furthermore, it has been reported that SDF-1 is expressed in the ischemic brain and facilitates the migration of transplanted cells into the ischemic zone [111, 112]. However, due to the low levels of endogenous SDF-1 receptor (CXCR4), stem cells migrate slowly toward the injury. Therefore, it was hypothesized that overexpression of CXCR4 might accelerate the mobilization of stem cells toward the ischemic area.

In this regard, $\mathrm{Yu}$ and co-workers [72] intravenously injected rat BM-MSCs over-expressing CXCR4, one day after $120 \mathrm{~min} \mathrm{MCAO}$ and the target parameters were evaluated 7 days post-ischemia. Analysis of eGFP-laballed stem cells showed that the percentage of migrating MSCs in the ischemic brain, especially within the ischemic boundary zone, was higher in the MSCs ${ }^{\text {CXCR4 }}$ group. Total neurological scores and infarct volume decreased in stem cell transplanted groups with better outcome in the CXCR4 over-expressing group. Also, co-staining of eGFP/neuron specific enolase (NSE), eGFP/GFAP and eGFP/vWF revealed that transplanted MSCs ${ }^{\mathrm{CXCR} 4}$ could differentiate into neurons, astrocytes and vascular-endothelial cells. An increased capillary vascular volume ratio was observed in the stem cell groups with a higher ratio in $\mathrm{MSCs}^{\mathrm{CXCR} 4}$.

In a very similar experiment, Bang and colleagues [73] just used human BM-MSCs over-expressing CXCR4. At days 3 and 7 post-ischemia, stem cell treated groups showed better mNSS compared to control. At a later time point (days 14), the degree of improvement was more pronounced in MSCs ${ }^{\text {CXCR4 }}$ than MSCs. However, MRI estimations of the lesion size showed no significant difference between the groups at day 14. Immunohistochemical stainings for human nuclear and also polymerase chain reaction for human chromosome 7 alphoid repeats were performed to evaluate the migration of stem cells. The obtained results showed that the migration of stem cells to the brain and in the ischemic boundary zone was improved in the genetically modified MSCs compared to naive ones, 3 days after injection.

Overall, transplantation of bone-marrow mesenchymal stem cells over-expressing CXCR4 might be a considerable approach in the treatment of cerebral infarction.

\section{Copper/zinc-superoxide Dismutase (SOD1)}

Copper/zinc-SOD is an oxidoreductase enzyme responsible for the very rapid two-step dismutation of the toxic superoxide radical to molecular oxygen and hydrogen peroxide, through alternate reduction and oxidation of the active-site copper.
Sakata et al. [74], isolated NSCs from postnatal day 1 wildtype, heterozygous SOD1 over-expressing and SOD1 knockout mice. Stem cells were injected into the cortex at 3 coordinates, two days after ischemia. NSCs-SOD1 reduced number of TUNEL-positive cells by $42 \%$ compared to NSCs in the peri-infarct cortex, 2 days after transplantation. Twenty-eight days after MCAO, the number of surviving GFP positive implanted cells in the injured brains was higher in the NSCs ${ }^{\mathrm{SOD} 1}$ group compared to NSCs group. In contrast, transplanted cell survival was lower in the knockout group than in the NSCs. At this time point, the percentage of beta III tubulin ${ }^{+}$neurons $(8.9 \pm 1.0,8.8 \pm 1.1,9.3 \pm 1.4)$ and $\mathrm{GFAP}^{+}$astrocytes $(40.1$ $\pm 4.3,37.1 \pm 5.9,38.3 \pm 8.0)$ differentiating from the implanted NSCs, was similar among the wild-type, SOD overexpressing and SOD knockout stem cells. To assess blood vessel density, 14 days after ischemia, DyLight 594-labeled Lycopersicon esculentum lectin were injected into the jugular vein and $30 \mathrm{~min}$ later animals were killed. Higher blood vessel density was observed in the NSCs ${ }^{\text {SOD1 }}$ group than in the nontransplanted and NSCs groups. However, enhanced angiogenesis was not observed in the wild-type and knockout groups. Similar results were also obtained by ELISA analysis of VEGF in the cortex, 4 days after stroke. Hematoxylin and eosin staining 28 days after ischemia showed that $\mathrm{NSCs}^{\mathrm{SOD} 1}$ decreased the cortical infarct size by 19.8 and $13.1 \%$ compared to non-transplanted and NSCs groups. No changes were observed in striatal infarct size among the experimental groups. According to the Rotarod test, functional improvements were observed in $\mathrm{NSCs}^{\mathrm{SOD} 1}$ compared to the nontransplanted and NSCs groups from day 7 and 21, respectively. However, statistical significance was not reached by the modified neurological severity scores. Significant behavioral improvement was not observed in the wild-type and knockout NSCs. Hence, SOD1 neural stem cells might represent a potential approach for improving the effectiveness of stem cell grafting in cerebral ischemia.

\section{Interleukin-10 (IL-10)}

IL-10 is a pleiotropic anti-inflammatory cytokine that regulates inflammatory responses. IL-10 is mainly synthesized by type- 2 helper $\mathrm{T}$ cells and inhibits pro-inflammatory cytokine release, $\mathrm{T}$ cell proliferation and macrophage activation [113]. It has been reported that intracerebroventricular injection of IL-10 [114] or using transgenic mice over-expressing murine IL-10 [115] ameliorated devastating conditions of stroke by upregulating anti-apoptotic proteins and attenuating pro-inflammatory signals.

In line with these studies, Nakajima et al. [75] intravenously injected human BM-MSCs over-expressing IL-10, at 0 or $3 \mathrm{~h}$ after $90 \mathrm{~min}$ MCAO. Quantitative analysis of infarct volume by TTC staining showed that the transplantation of stem cells immediately after MCAO led to reduction of infarct size 
3 and 7 days after stroke, with better results in MSCs ${ }^{\mathrm{IL} 10}$. However, when stem cells were injected $3 \mathrm{~h}$ after MCAO, $\mathrm{MSCs}^{\mathrm{IL} 10}$ reduced the infarct area, when compared to MSCs and control groups. Stem cell therapy immediately after MCAO led to improvements in neurological scores and motor function 7 days after stroke. However, when stem cells were injected $3 \mathrm{~h}$ after MCAO, MSCs ${ }^{\mathrm{IL} 10}$ improved posture score, hemiparesis score and rotarod performance (see Box 2). Immunostaining against ionized calcium binding adaptor molecule 1 (marker of microglial activation), TNF $\alpha$ (proinflammatory cytokine) and Fluoro-Jade C (marker of neurodegeneration) in the cortical ischemic boundary zone showed fewer numbers of positive cells in the stem cell-transplanted groups compared to control at 24 and $72 \mathrm{~h}$ after ischemia; the reduction was markedly lower in MSCs ${ }^{\mathrm{IL} 10}$ group. Similar results were obtained by ELISA in the levels of IL- 6 , IL- $1 \beta$ and TNF $\alpha$ in the ischemic hemisphere extracts at $72 \mathrm{~h}$ post-ischemia. Finally, quantification of engrafted MSCs using real-time polymerase chain reaction with human-specific Alu sequences showed higher expression in MSCs ${ }^{\mathrm{IL} 10}$ than MSCs at 3 and 7 days after ischemia in the ipsilateral hemisphere. Thus, obtained results suggest that MSCs ${ }^{\mathrm{IL} 10}$ enhance neuroprotective effects of naive MSCs by anti-inflammatory modulation.

\section{Survivin (SVV)}

SVV is one of the members of the apoptosis inhibitor family. The SVV protein functions to inhibit caspase activation, therefore causing negative regulation of programmed cell death or apoptosis. It has been reported that SVV-modified MSCs can further improve the cardiac performance of rats after myocardial infarction by enhancing survival of the transplanted cells [116]. Therefore, Liu et al. [76] evaluated therapeutic potential of rat BM-MSCs over-expressing SVV in the rat model of stroke induced by 120 min MCAO. Stem cells were transplanted into tail vein $24 \mathrm{~h}$ after ischemia. Number of the GFP-positive MSCs in the SVV group elevated by about 1.3-fold at 4 days after administration, and by 3.4-fold at 14 days after administration in MSC group. There were very few GFP-positive cells co-expressing NeuN in the stem cell transplantation groups. Stem cell administration resulted in higher protein expression levels of VEGF and FGF-2 in the injured cerebral tissue, 4 days after cell therapy; however, just MSCs ${ }^{\mathrm{SVV}}$ could elevate the target protein levels at day 14. TTC staining, fourteen days after transplantation, showed reduced infarct size in the stem cell treated groups compared to non-transplanted control with higher reduction in the MSCs ${ }^{\mathrm{SVV}}$ group. Similar patterns were also observed in the behavioral improvements at this time point. Accordingly, over-expression of survivin might be able to enhance therapeutic effects of mesenchymal stem cells in the ischemic brain, possibly through increasing the survival capacity of grafted stem cells and regulating of protective cytokines expression.

\section{Over-expression of microRNAs}

\section{microRNA 133b (miR-133b)}

miRNAs are 18-25 nucleotide, non-protein coding, evolutionarily conserved, transcripts that control gene expression via translational repression or mRNA degradation or both. miRNAs exert key roles in variety of regulatory mechanisms including host-pathogen interactions and developmental timing as well as tumorigenesis, apoptosis, proliferation and differentiation in different organisms [117].

In this regard, Xin et a. [77] used rat BM-MSCs, genetically modified for miR-133b in a rat model of cerebral ischemia. Stem cells were injected via the tail vein one day after $120 \mathrm{~min}$ MCAO. Although, MSCs improved adhesive-removal and foot-fault functional scores (see Box 2) compared to nontransplanted control 14 days after stroke, functional improvements in the MSCs ${ }^{\text {miR133b }}$ group were seen from day 7 on with a better outcome at day 14. Intracortical axonal density was increased in the MSCs compared to control group at day 14 after MCAO. MSCs ${ }^{\text {miR133 }}$ treatment further increased cortical axonal density at this time point compared to MSC. Compared to control, the positive areas of synaptophysin (marker for synapses), NF-200 (marker for apical dendrites of large cortical pyramidal neurons) and Bielshowsky silver (marker of neuronal fibers) staining increased at day 14 following ischemia along the ischemic boundary zone in the MSC treated group. $\mathrm{MSCs}^{\mathrm{miR} 133}$ enhanced the positive areas compared to MSC.

In another study, Huang and co-workers [78] intravenously transplanted rat BM-MSCs genetically modified for miR$133 \mathrm{~b}$, three days after 90 min MCAO. Only MSCs ${ }^{\text {miR } 133}$ could improve the modified neurological severity score, 14 days after treatment. Also, immunostaining against NeuN showed that exogenous stem cells survived and differentiated to neurons; however, the differentiation potential of MSCs is unaffected by miR-133b modification.

Altogether, manipulation of bone-marrow mesenchymal stem cells to over-express microRNAs e.g. miR-133b, might be a remarkable therapeutic strategy to improve cell homing and motor recovery.

\section{Gene Delivery Systems, Pros and Cons}

In order to over-express desired gene(s) in stem cells to enhance their therapeutic potential in the context of cerebral ischemia, various viral and non-viral gene delivery systems have been used to transfect stem cells (Table 2). Viral gene transferring systems are designed based on the ability of viruses to insert their genetic material into the host cell. For this purpose, several viral vectors such as herpes simplex viruses, adeno-associated viruses, adenoviruses, retroviruses and lentiviruses have been widely employed. Due to the permanent 
Table 2 Gene delivery vectors that have been used to over-express target gene(s) in stem cells to treat animal models of stroke

\begin{tabular}{|c|c|}
\hline Delivered gene & Gene delivery vector(s) [Ref.] \\
\hline BDNF & $\begin{array}{l}\text { - Adenovirus } \\
\text { pWEAxCAhBDNF-F/RGD [39, 40, 49] } \\
\text { pShuttleCMV-BDNF [45] } \\
\text { pAd-HM41-K7-BDNF-IE [46] } \\
\text { - Retrovirus } \\
\text { pBABE-BDNF [41, 44] } \\
\text { pLXSN-BDNF-GFP [42] } \\
\text { - Lentivirus [43] }\end{array}$ \\
\hline NT-3 & $\begin{array}{l}\text { - Retrovirus } \\
\text { pLIA-NT3 [47] } \\
\text { • Lentivirus } \\
\text { pGC-E1-hNT3 [48] } \\
\text { - Adenovirus } \\
\text { AxCAhNT3-F/RGD [49] }\end{array}$ \\
\hline GDNF & $\begin{array}{l}\text { - Adenovirus } \\
\text { AxCAhGDNF-F/RGD [49, 50] } \\
\text { pAdEasy-1-pAdTrack CMV-GDNF [51] } \\
\text { • Non-viral plasmid }[52,53]\end{array}$ \\
\hline VEGF & $\begin{array}{l}\text { - Herpes Simplex Virus } \\
\text { 1764/4-/pR19/hVEGF165 [54] } \\
\text { • Retrovirus } \\
\text { pLPCX.VEGF [55] } \\
\text { • Adenovirus } \\
\text { pWEAxCAhVEGF-F/RGD [57] }\end{array}$ \\
\hline CNTF & $\begin{array}{l}\text { - Adenovirus } \\
\text { AxCAhCNTF-F/RGD [49] }\end{array}$ \\
\hline EGFL-7 & $\begin{array}{l}\text { • Adenovirus } \\
\text { pAd-HM41-K7-EGFL7-IE [46] }\end{array}$ \\
\hline Ang1 & $\begin{array}{l}\text { - Adenovirus } \\
\text { pWAxCAhAng1-F/RGD [56, 57] }\end{array}$ \\
\hline PIGF & $\begin{array}{l}\text { • Adenovirus } \\
\text { pWEAxCAhP1GF-F/RGD [58] }\end{array}$ \\
\hline $\mathrm{HIF} 1 \alpha$ & $\begin{array}{l}\text { - Adenovirus [59, 61, 62] } \\
\text { - Lentivirus } \\
\text { Lv-mHIF-1 } \alpha \text {-EGFP [60] } \\
\text { pCDH-CMV-HIF1-T2A-EGFP [71] }\end{array}$ \\
\hline FGF & $\begin{array}{l}\text { • Herpes Simplex Virus } \\
1764 /-4 / \text { pR19/ssIL2-FGF-2 [64] } \\
\text { • Lentivirus [66] } \\
\text { • Non-viral plasmid [65] }\end{array}$ \\
\hline HGF & $\begin{array}{l}\text { • Herpes Simplex Virus } \\
\text { pR19ratHGFKT3WPRE [67] }\end{array}$ \\
\hline Akt1 & $\begin{array}{l}\text { - Retrovirus } \\
\text { pLHCX-Akt1 [69] } \\
\text { - Lentivirus } \\
\text { pCDH-CMV-Akt1-T2A-EGFP [71] }\end{array}$ \\
\hline $\mathrm{Bcl} 2 / \mathrm{Bcl}-\mathrm{xl}$ & $\begin{array}{l}\text { - Non-viral plasmid [70] } \\
\text { • Lentivirus } \\
\text { pCDH-CMV-Bcl2-T2A-EGFP [71] } \\
\text { pCDH-CMV-Bcl-xl-T2A-EGFP [71] }\end{array}$ \\
\hline CXCR4 & $\begin{array}{l}\text { • Lentivirus } \\
\text { pNL-CXCR4-IRES2-eGFP [72] } \\
\text { • Adenovirus } \\
\text { Ad5/35EF1 } \alpha \text {-CXCR4 [73] }\end{array}$ \\
\hline IL-10 & $\begin{array}{l}\text { - Adeno-associated virus } \\
\text { dsAAV1-CAG-IL-10 [75] }\end{array}$ \\
\hline Survivin & • Lentivirus [76] \\
\hline Persephin & $\begin{array}{l}\text { • Adenovirus } \\
\text { pAd-HM41-K7-PSP-IE [46] }\end{array}$ \\
\hline Sonic hedgehog & $\begin{array}{l}\text { • Adenovirus } \\
\text { pAd-HM41-K7-SHH-IE [46] }\end{array}$ \\
\hline MiR-133 & $\begin{array}{l}\text { - Lentivirus } \\
\text { LentimiRa-GFP-hsa-miR-133b [77] } \\
\text { - Non-viral plasmid [78] }\end{array}$ \\
\hline
\end{tabular}

integration of exogenous genes into the host genome (retroviruses and lentiviruses) or as persistent extrachromosomal episomes (herpes viruses, adeno-associated viruses and adenoviruses), these strategies are usually more effective than the transient transfection of plasmids. However, their clinical application is limited by their inherent potential oncogenicity, toxicity, and immunogenicity. Non-viral vectors are developed to prevent adverse side effects; however, the transfection efficiency of non-viral plasmids is significantly lower than of viral carriers. Benefits and limitations of each individual gene delivery system for clinical applications are thoroughly reviewed elsewhere [118, 119].

\section{Epidermal Neural Crest Stem Cells as a Promising Candidate in Stroke}

Based on the above presented studies, BM-MSCs and neural stem cells are the most abundantly used cell-types that can be genetically modified to enhance their potential when transplanted in animal models of stroke. However, our investigations revealed that epidermal neural crest stem cells (EPINCSCs) can also benefit the inhospitable context of rat model of ischemic stroke [37] as well as ex vivo [120] and in vivo [121] models of spinal cord injury. EPI-NCSCs are located in the bulge area of the hair follicle, and retain the differentiation potential of their neural crest origin, so that they can differentiate into neural lineages [122]. Unlike BM-MSCs [123], that their proliferation and differentiation capacity dramatically decline with aging, recent reports revealed that EPI-NCSCs of aged donors can maintain their multipotency both in vitro and in vivo [124]. This advantage over BM-MSCs supports the application of these stem cells to elderly individuals, who have an increased incidence of stroke. According to accumulating evidence, EPI-NCSCs express several trophic factors, which their rate of expression can be manipulated through the use of different preconditioning strategies [125-129] to achieve optimum efficiency after transplantation. In addition, administration of EPI-NCSCs via intra-arterial or intra venous routes following reperfusion, created a comparable outcome to intra-arterial grafted BM-MSCs, 7 days after cerebral ischemia [37]. It has been implicated that grafted EPI-NCSCs are mostly acting through the secretion of various trophic factors such as BDNF, GDNF, NT3, NGF and VEGF that can impose different modulatory functions [130]. Interestingly, according to unpublished data from our group, the expression level of all aforementioned trophic factors, except NT3, is higher than cultured astrocytes. This striking data supports the beneficial function of these grafted stem cells in damaged tissues. Furthermore, EPI-NCSCs showed superior immunomodulation properties in animal models of nerve injury and stroke, as they upregulated the anti-inflammatory cytokines, whilst reducing the expression of pro- 
inflammatory cytokines [37, 131, 132]. Since EPI-NCSCs can easily be transduced to overexpress GFP [133], genetic manipulations to elevate neurotrophic factor expression seems feasible, and with this review we hope to prompt further studies investigating the beneficial characteristics of those cells. Taken together, owing to neuromodulatory properties of EPINCSCs and their ability to release trophic factors, these stem cells can be considered as a promising cell type to treat various conditions such as stroke or even the newly widespread COVID-19 infections [134, 135].

\section{Clinical Application of Genetically Engineered Stem Cells for Stroke}

Based on the US National Library of Medicine (ClinicalTrials.gov) as well as the International Clinical Trials Registry Platform, around 100 cell-therapy based clinical trials have been performed for stroke [136]. Nevertheless, very few clinical trials have been conducted by using genetically modified stem cells to treat stroke patients [137]. For instance, Steinberg et al. [138] employed modified BMMSCs called SB623 cells that were transiently transfected with a plasmid coding for the intracellular domain of human Notch-1. A total of 18 patients received 2.5, 5 or 10 million cells stereotactically (into the infarct area), six to sixty months after the onset of stroke. The authors reported that the SB623 therapy significantly improved functional recovery in the National Institutes of Health Stroke Scale, Fugl-Meyer motor function total score, Fugl-Meyer total score and European Stroke Scale.

Although genetically engineered stem cells are widely used in pre-clinical investigations, there are lots of limitations and unsolved issues for their clinical application: what are the best types of stem cells and which sources should have been used for genetic engineering? What are the best gene delivery systems regarding the safety and efficiency? What are the adequate target genes that should be modified in stem cells? How many modified stem cells should be administered, and through which route? What is the best treatment window after stroke, and what kind of patient should receive the treatment (Fig. 4)? In addition, safety and quality control aspects of overexpressing genes should be carefully considered as well. For example, the overexpression of one gene might also affect other related pathways, resulting in unwanted side effects. Moreover, chemical reagents using for transfection, vector
Fig. 4 Unsolved issues for clinical application of genetically engineered stem cells

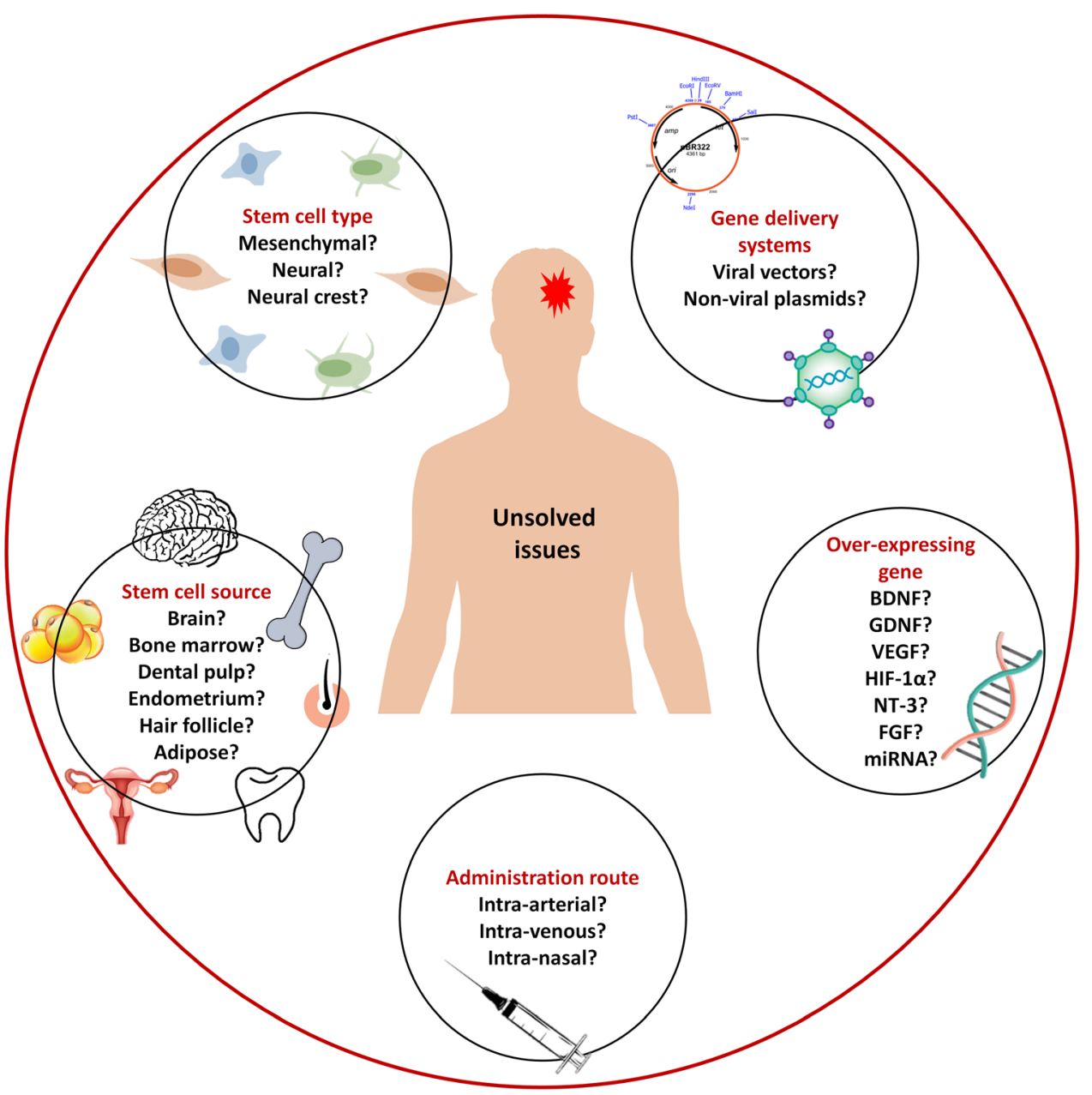


backbone sequences, reporter and antibiotic resistance genes, as well as antibiotic treatment may evoke off-target effects and/or artifacts [139].

\section{Conclusions}

Up until now, therapeutic benefits of a wide variety of stem cells have been demonstrated in the context of stroke. Furthermore, as reviewed here, genetically modified stem cells over-expressing specific proteins, could elevate the restorative potential of naive stem cells, by the enhanced survival/differentiation potential of transplanted cells, apoptosis inhibition, infarct volume reduction or neovascularization which eventually may lead to functional improvements. Among the different cell types that were discussed here, epidermal neural crest stem cells are attractive candidate that can be considered for genetic modifications in the context of stroke, due to their expression profile of neurotrophic factors and neuromodulatory cytokines. In addition, since the majority of investigations have focused on the short-term curative effects of genetically engineered stem cells, further studies are required to clarify their long-term impacts.

\footnotetext{
Author Contributions MSS: manuscript writing

SP: manuscript writing

EH: literature search, article screening and selection

MO: literature search, article screening and selection

MB: literature search, article screening and selection

SSZ: literature search, article screening and selection

AS: critically revised the manuscript

$\mathrm{BJ}$ : critically revised the manuscript

ABH: critically revised the manuscript

JAM: critically revised the manuscript
}

Funding This study was financially supported by Shiraz University of Medical Sciences (grant number: 99-01-106-23536). Partial support was also provided by International Brain Research Organization (IBRO) Research Fellowship 2019 and Iran National Science Foundation (INSF:96016991), received by the first author.

Data Availability Not applicable.

\section{Declarations}

Ethical Approval Not applicable.

Consent to Participate Not applicable.

Consent to Publish Not applicable.

Competing Interests The authors have no conflicts of interest to declare that are relevant to the content of this article.

\section{References}

1. Johnson, C. O., Nguyen, M., Roth, G. A., Nichols, E., Alam, T., Abate, D., et al. (2019). Global, regional, and national burden of stroke, 1990-2016: a systematic analysis for the Global Burden of Disease Study 2016. The Lancet Neurology, 18(5), 439-458.

2. Borhani-Haghighi, A., Safari, R., Heydari, S. T., Soleimani, F., Sharifian, M., Kashkuli, S. Y., et al. (2013). Hospital mortality associated with stroke in southern Iran. Iranian Journal of Medical Sciences, 38(4), 314.

3. Shahtaheri, R. A., Borhani Haghighi, A., Safari, A., Cruz-Flores, S. (2012). Recombinant tissue plasminogen activator (rtPA) and stroke unit for acute ischaemic stroke in developing countries, are they cost-effective? International Journal of Stroke, 7(7), E9-E9.

4. Rhim, T., \& Lee, M. (2016). Targeted delivery of growth factors in ischemic stroke animal models. Expert Opinion on Drug Delivery, 13(5), 709-723.

5. Safari, A., Safari, R., \& Borhani-Haghighi, A. (2016). Immunology of stroke. Galen Medical Journal, 5(Suppl 1), 10 17.

6. Chrostek, M. R., Fellows, E. G., Crane, A. T., Grande, A. W., \& Low, W. C. (2019). Efficacy of stem cell-based therapies for stroke. Brain Research, 1722, 146362.

7. Fernandez-Susavila, H., Bugallo-Casal, A., Castillo, J., \& Campos, F. (2019). Adult stem cells and induced pluripotent stem cells for stroke treatment. Frontiers in Neurolog, 10, 908.

8. Wang, F., Tang, H., Zhu, J., \& Zhang, J. H. (2018). Transplanting mesenchymal stem cells for treatment of ischemic stroke. Cell Transplantation, 27(12), 1825-1834.

9. Yang, Z., Zhu, L., Li, F., Wang, J., Wan, H., \& Pan, Y. (2014). Bone marrow stromal cells as a therapeutic treatment for ischemic stroke. Neuroscience Bulletin, 30(3), 524-534.

10. Dulamea, A. O. (2015). The potential use of mesenchymal stem cells in stroke therapy-from bench to bedside. Journal of the Neurological Sciences, 352(1-2), 1-11.

11. Lucia Maria Ferri, A., Bersano, A., Lisini, D., Boncoraglio, G., Frigerio, S., Parati, E. (2016). Mesenchymal stem cells for ischemic stroke: progress and possibilities. Current Medicinal Chemistry, 23(16), 1598-1608.

12. Hsuan, Y. C. Y., Lin, C. H., Chang, C. P., \& Lin, M. T. (2016). Mesenchymal stem cell-based treatments for stroke, neural trauma, and heat stroke. Brain and Behavior, 6(10), e00526.

13. Jiang, J., Wang, Y., Liu, B., Chen, X., \& Zhang, S. (2018). Challenges and research progress of the use of mesenchymal stem cells in the treatment of ischemic stroke. Brain and Development, 40(7), 612-626.

14. Toyoshima, A., Yasuhara, T., \& Date, I. (2017). Mesenchymal stem cell therapy for ischemic stroke. Acta Medica Okayama, 71(4), 263-268.

15. Turnbull, M. T., Zubair, A. C., Meschia, J. F., \& Freeman, W. D. (2019). Mesenchymal stem cells for hemorrhagic stroke: status of preclinical and clinical research. NPJ Regenerative Medicine, 4(1), 1-10

16. Li, G., Yu, F., Lei, T., Gao, H., Li, P., Sun, Y., et al. (2016). Bone marrow mesenchymal stem cell therapy in ischemic stroke: mechanisms of action and treatment optimization strategies. Neural Regeneration Research, 11(6), 1015-1024.

17. Kuroda, S. (2016). Current opinion of bone marrow stromal cell transplantation for Ischemic stroke. Neurologia MedicoChirurgica, 56(6), 293-301.

18. Gutiérrez-Fernández, M., Otero-Ortega, L., Ramos-Cejudo, J., Rodríguez-Frutos, B., Fuentes, B., \& Díez-Tejedor, E. (2015). Adipose tissue-derived mesenchymal stem cells as a strategy to improve recovery after stroke. Expert Opinion on Biological Therapy, 15(6), 873-881. 
19. Li, Y., Hu, G., \& Cheng, Q. (2015). Implantation of human umbilical cord mesenchymal stem cells for ischemic stroke: perspectives and challenges. Frontiers of Medicine, 9(1), 20-29.

20. Baker, E. W., Kinder, H. A., \& West, F. D. (2019). Neural stem cell therapy for stroke: A multimechanistic approach to restoring neurological function. Brain and Behavior, 9(3), e01214.

21. Bernstock, J. D., Peruzzotti-Jametti, L., Ye, D., Gessler, F. A., Maric, D., Vicario, N., et al. (2017). Neural stem cell transplantation in ischemic stroke: a role for preconditioning and cellular engineering. Journal of Cerebral Blood Flow \& Metabolism, 37(7), 2314-2319.

22. Boese, A. C., Le, Q.-S. E., Pham, D., Hamblin, M. H., \& Lee, J.-P. (2018). Neural stem cell therapy for subacute and chronic ischemic stroke. Stem Cell Research \& Therapy, 9(1), 1-17.

23. Sinden, J. D., Hicks, C., Stroemer, P., Vishnubhatla, I., \& Corteling, R. (2017). Human neural stem cell therapy for chronic ischemic stroke: charting progress from laboratory to patients. Stem Cells and Development, 26(13), 933-947.

24. Zhang, G.-L., Zhu, Z.-H., \& Wang, Y.-Z. (2019). Neural stem cell transplantation therapy for brain ischemic stroke: Review and perspectives. World Journal of Stem Cells, 11(10), 817.

25. Chen, L., Zhang, G., Gu, Y., \& Guo, X. (2016). Meta-analysis and systematic review of neural stem cells therapy for experimental ischemia stroke in preclinical studies. Scientific Reports, 6, 32291.

26. Zhang, L., Tao, W., Feng, H., \& Chen, Y. (2017). Transcriptional and genomic targets of neural stem cells for functional recovery after hemorrhagic stroke. Stem Cells International, 2017, 2412890.

27. Kumar, A., Prasad, M., Jali, V., Pandit, A., Misra, S., Kumar, P., et al. (2017). Bone marrow mononuclear cell therapy in ischaemic stroke: a systematic review. Acta Neurologica Scandinavica, 135(5), 496-506.

28. Vahidy, F. S., Rahbar, M. H., Zhu, H., Rowan, P. J., Bambhroliya, A. B., \& Savitz, S. I. (2016). Systematic review and meta-analysis of bone marrow-derived mononuclear cells in animal models of ischemic stroke. Stroke, 47(6), 1632-1639.

29. Zhu, Y., Wan, S., \& Zhan, R. (2012). Inducible pluripotent stem cells for the treatment of ischemic stroke: current status and problems. Reviews in the Neurosciences, 23(4), 393-402.

30. Kokaia, Z., Tornero, D., Lindvall, O. (2017). Transplantation of reprogrammed neurons for improved recovery after stroke. Progress in Brain Research (231, p. 245-263). Elsevier.

31. Yu, F., Li, Y., Morshead, M. C. (2013). Induced pluripotent stem cells for the treatment of stroke: the potential and the pitfalls. Current Stem Cell Research \& Therapy, 8(5), 407-414.

32. Zents, K., \& Copray, S. (2016). The therapeutic potential of induced pluripotent stem cells after stroke: evidence from rodent models. Current Stem Cell Research \& Therapy, 11(2), 166-174.

33. Gancheva, M. R., Kremer, K. L., Gronthos, S., \& Koblar, S. A. (2019). Using dental pulp stem cells for stroke therapy. Frontiers in Neurology, 10, 422.

34. Lan, X., Sun, Z., Chu, C., Boltze, J., \& Li, S. (2019). Dental pulp stem cells: an attractive alternative for cell therapy in ischemic stroke. Frontiers in Neurology, 10, 824.

35. Rodrigues, M. C. O., Lippert, T., Nguyen, H., Kaelber, S., Sanberg, P. R., \& Borlongan, C. V. (2016). Menstrual bloodderived stem cells: in vitro and in vivo characterization of functional effects (pp. 111-121). Biobanking: Springer.

36. Rodrigues, M. C. O., Dmitriev, D., Rodrigues jr, A., Glover, L. E., Sanberg, P. R., Allickson, J. G., et al. (2012). Menstrual blood transplantation for ischemic stroke: therapeutic mechanisms and practical issues. Interventional Medicine and Applied Science, 4(2), 59-68.

37. Salehi, M. S., Pandamooz, S., Safari, A., Jurek, B., Tamadon, A., Namavar, M. R., et al. (2020). Epidermal neural crest stem cell transplantation as a promising therapeutic strategy for ischemic stroke. CNS Neuroscience \& Therapeutics, 26(7), 670-681.

38. Lin, L., \& Du, L. (2018). The role of secreted factors in stem cellsmediated immune regulation. Cellular Immunology, 326, 24-32.

39. Kurozumi, K., Nakamura, K., Tamiya, T., Kawano, Y., Kobune, M., Hirai, S., et al. (2004). BDNF gene-modified mesenchymal stem cells promote functional recovery and reduce infarct size in the rat middle cerebral artery occlusion model. Molecular Therapy, 9(2), 189-197.

40. Nomura, T., Honmou, O., Harada, K., Houkin, K., Hamada, H., \& Kocsis, J. (2005). IV infusion of brain-derived neurotrophic factor gene-modified human mesenchymal stem cells protects against injury in a cerebral ischemia model in adult rat. Neuroscience, 136(1), 161-169.

41. Lee, H. J., Lim, I. J., Lee, M. C., \& Kim, S. U. (2010). Human neural stem cells genetically modified to overexpress brainderived neurotrophic factor promote functional recovery and neuroprotection in a mouse stroke model. Journal of Neuroscience Research, 88(15), 3282-3294.

42. Zhu, J., Zhao, Y., Chen, S., Zhang, W., Lou, L., \& Jin, X. (2011). Functional recovery after transplantation of neural stem cells modified by brain-derived neurotrophic factor in rats with cerebral ischaemia. Journal of International Medical Research, 39(2), 488-498.

43. Tao, J., Ji, F., Liu, B., Wang, F., Dong, F., \& Zhu, Y. (2012). Improvement of deficits by transplantation of lentiviral vectormodified human amniotic mesenchymal cells after cerebral ischemia in rats. Brain Research, 1448, 1-10.

44. Chang, D.-J., Lee, N., Choi, C., Jeon, I., Oh, S.-H., Shin, D. A., et al. (2013). Therapeutic effect of BDNF-overexpressing human neural stem cells (HB1. F3. BDNF) in a rodent model of middle cerebral artery occlusion. Cell Transplantation, 22(8), 14411452.

45. Jeong, C. H., Kim, S. M., Lim, J. Y., Ryu, C. H., Jun, J., \& Jeun, S.-S. (2014). Mesenchymal stem cells expressing brain-derived neurotrophic factor enhance endogenous neurogenesis in an ischemic stroke model. BioMed Research International, 2014:129145.

46. Van Velthoven, C. T., Braccioli, L., Willemen, H. L., Kavelaars, A., \& Heijnen, C. J. (2014). Therapeutic potential of genetically modified mesenchymal stem cells after neonatal hypoxic-ischemic brain damage. Molecular Therapy, 22(3), 645-654.

47. Park, K. I., Himes, B. T., Stieg, P. E., Tessler, A., Fischer, I., \& Snyder, E. Y. (2006). Neural stem cells may be uniquely suited for combined gene therapy and cell replacement: evidence from engraftment of neurotrophin-3-expressing stem cells in hypoxicischemic brain injury. Experimental Neurology, 199(1), 179-190.

48. Zhang, Z., Wang, R., Li, G., Wei, J., Li, Z., Feng, M., et al. (2008). Transplantation of neural stem cells modified by human neurotrophin-3 promotes functional recovery after transient focal cerebral ischemia in rats. Neuroscience Letters, 444(3), 227-230.

49. Kurozumi, K., Nakamura, K., Tamiya, T., Kawano, Y., Ishii, K., Kobune, M., et al. (2005). Mesenchymal stem cells that produce neurotrophic factors reduce ischemic damage in the rat middle cerebral artery occlusion model. Molecular Therapy, 11(1), 96104.

50. Horita, Y., Honmou, O., Harada, K., Houkin, K., Hamada, H., \& Kocsis, J. D. (2006). Intravenous administration of glial cell linederived neurotrophic factor gene-modified human mesenchymal stem cells protects against injury in a cerebral ischemia model in the adult rat. Journal of Neuroscience Research, 84(7), 14951504.

51. Chen, B., Gao, X.-Q., Yang, C.-X., Tan, S.-K., Sun, Z.-L., Yan, N.-H., et al. (2009). Neuroprotective effect of grafting GDNF gene-modified neural stem cells on cerebral ischemia in rats. Brain Research, 1284, 1-11. 
52. Ou, Y., Yu, S., Kaneko, Y., Tajiri, N., Bae, E. C., Chheda, S. H., et al. (2010). Intravenous infusion of GDNF gene-modified human umbilical cord blood CD34 + cells protects against cerebral ischemic injury in spontaneously hypertensive rats. Brain Research, 1366, 217-225.

53. Wang, Y., Geng, T., Ni, A., Yin, H., \& Han, B. (2011). Effects of transplanted GDNF gene modified marrow stromal cells on focal cerebral ischemia in rats. Frontiers in Integrative Neuroscience, 5, 89.

54. Miki, Y., Nonoguchi, N., Ikeda, N., Coffin, R. S., Kuroiwa, T., \& Miyatake, S.-I. (2007). Vascular endothelial growth factor genetransferred bone marrow stromal cells engineered with a herpes simplex virus type 1 vector can improve neurological deficits and reduce infarction volume in rat brain ischemia. Neurosurgery, 61(3), 586-595.

55. Lee, H. J., Kim, K. S., Park, I. H., \& Kim, S. U. (2007). Human neural stem cells over-expressing VEGF provide neuroprotection, angiogenesis and functional recovery in mouse stroke model. PLoS One, 2(1), e156.

56. Onda, T., Honmou, O., Harada, K., Houkin, K., Hamada, H., \& Kocsis, J. D. (2008). Therapeutic benefits by human mesenchymal stem cells (hMSCs) and Ang-1 gene-modified hMSCs after cerebral ischemia. Journal of Cerebral Blood Flow \& Metabolism, $28(2), 329-340$.

57. Toyama, K., Honmou, O., Harada, K., Suzuki, J., Houkin, K., Hamada, H., et al. (2009). Therapeutic benefits of angiogenetic gene-modified human mesenchymal stem cells after cerebral ischemia. Experimental Neurology, 216(1), 47-55.

58. Liu, H., Honmou, O., Harada, K., Nakamura, K., Houkin, K., Hamada, H., et al. (2006). Neuroprotection by PlGF genemodified human mesenchymal stem cells after cerebral ischaemia. Brain, 129(10), 2734-2745.

59. Wu, W., Chen, X., Hu, C., Li, J., Yu, Z., \& Cai, W. (2010). Transplantation of neural stem cells expressing hypoxiainducible factor- $1 \alpha(\mathrm{HIF}-1 \alpha)$ improves behavioral recovery in a rat stroke model. Journal of Clinical Neuroscience, 17(1), 92-95.

60. Ye, Z., Ye, W., Deng, Y., Wang, J., Zhou, G., \& Zhang, X. (2013). HIF-1-modified BMSCs improve migration and reduce neuronal apoptosis after stroke in rats. Chinese Science Bulletin, 58(28-29), 3519-3528.

61. Yang, C., Liu, H., \& Liu, D. (2014). Mutant hypoxia-inducible factor $1 \alpha$ modified bone marrow mesenchymal stem cells ameliorate cerebral ischemia. International Journal of Molecular Medicine, 34(6), 1622-1628.

62. Ye, H., Chen, M., \& Wu, W. (2016). Transplantation of hypoxiainducible factor- $1 \alpha$ gene modified neural stem cells increases cell survival and angiogenesis after cerebral ischemia. Stem Cell and Translational Investigation, 3, e1429.

63. Lin, D., Zhou, L., Wang, B., Liu, L., Cong, L., Hu, C., et al. (2017). Overexpression of HIF-1 $\alpha$ in mesenchymal stem cells contributes to repairing hypoxic-ischemic brain damage in rats. Comptes Rendus Biologies, 340(1), 18-24.

64. Ikeda, N., Nonoguchi, N., Zhao, M. Z., Watanabe, T., Kajimoto, Y., Furutama, D., et al. (2005). Bone marrow stromal cells that enhanced fibroblast growth factor-2 secretion by herpes simplex virus vector improve neurological outcome after transient focal cerebral ischemia in rats. Stroke, 36(12), 2725-2730.

65. Ghazavi, H., Hoseini, S. J., Ebrahimzadeh-Bideskan, A., Mashkani, B., Mehri, S., Ghorbani, A., et al. (2017). Fibroblast growth factor type 1 (FGF1)-overexpressed adipose-derived mesenchaymal stem cells (AD-MSC FGF1) induce neuroprotection and functional recovery in a rat stroke model. Stem Cell Reviews and Reports, 13(5), 670-685.

66. Zhang, J.-J., Zhu, J.-J., Hu, Y.-B., Xiang, G.-H., Deng, L.-C., Wu, F.-Z., et al. (2017). Transplantation of bFGF-expressing neural stem cells promotes cell migration and functional recovery in rat brain after transient ischemic stroke. Oncotarget, 8(60), 102067.

67. Zhao, M.-Z., Nonoguchi, N., Ikeda, N., Watanabe, T., Furutama, D., Miyazawa, D., et al. (2006). Novel therapeutic strategy for stroke in rats by bone marrow stromal cells and ex vivo HGF gene transfer with HSV-1 vector. Journal of Cerebral Blood Flow \& Metabolism, 26(9), 1176-1188.

68. Huang, X., Ding, J., Li, Y., Liu, W., Ji, J., Wang, H., et al. (2018). Exosomes derived from PEDF modified adipose-derived mesenchymal stem cells ameliorate cerebral ischemia-reperfusion injury by regulation of autophagy and apoptosis. Experimental Cell Research, 371(1), 269-277.

69. Lee, H. J., Kim, M. K., Kim, H. J., \& Kim, S. U. (2009). Human neural stem cells genetically modified to overexpress Akt1 provide neuroprotection and functional improvement in mouse stroke model. PLoS One, 4(5), e5586.

70. Wei, L., Cui, L., Snider, B. J., Rivkin, M., Steven, S. Y., Lee, C.S., et al. (2005). Transplantation of embryonic stem cells overexpressing Bcl-2 promotes functional recovery after transient cerebral ischemia. Neurobiology of Disease, 19(1-2), 183-193.

71. Korshunova, I., Rhein, S., Garcia-Gonzalez, D., Stolting, I., Pfisterer, U., Barta, A., et al. (2020). Genetic modification increases the survival and the neuroregenerative properties of transplanted neural stem cells. JCI Insight, 5(4):e126268.

72. Yu, X., Chen, D., Zhang, Y., Wu, X., Huang, Z., Zhou, H., et al. (2012). Overexpression of CXCR4 in mesenchymal stem cells promotes migration, neuroprotection and angiogenesis in a rat model of stroke. Journal of the Neurological Sciences, 316(1-2), 141-149.

73. Bang, O. Y., Jin, K. S., Hwang, M. N., Kang, H. Y., Kim, B. J., Lee, S. J., et al. (2012). The effect of CXCR4 overexpression on mesenchymal stem cell transplantation in ischemic stroke. Cell Medicine, 4(2), 65-76.

74. Sakata, H., Niizuma, K., Wakai, T., Narasimhan, P., Maier, C. M., \& Chan, P. H. (2012). Neural stem cells genetically modified to overexpress cu/zn-superoxide dismutase enhance amelioration of ischemic stroke in mice. Stroke, 43(9), 2423-2429.

75. Nakajima, M., Nito, C., Sowa, K., Suda, S., Nishiyama, Y., Nakamura-Takahashi, A., et al. (2017). Mesenchymal stem cells overexpressing interleukin-10 promote neuroprotection in experimental acute ischemic stroke. Molecular Therapy-Methods \& Clinical Development, 6, 102-111.

76. Liu, N., Zhang, Y., Fan, L., Yuan, M., Du, H., Cheng, R., et al. (2011). Effects of transplantation with bone marrow-derived mesenchymal stem cells modified by Survivin on experimental stroke in rats. Journal of Translational Medicine, 9(1), 105.

77. Xin, H., Li, Y., Liu, Z., Wang, X., Shang, X., Cui, Y., et al. (2013). MiR-133b promotes neural plasticity and functional recovery after treatment of stroke with multipotent mesenchymal stromal cells in rats via transfer of exosome-enriched extracellular particles. Stem Cells, 31(12), 2737-2746.

78. Huang, B., Jiang, X.-C., Zhang, T.-Y., Hu, Y.-L., Tabata, Y., Chen, Z., et al. (2017). Peptide modified mesenchymal stem cells as targeting delivery system transfected with miR-133b for the treatment of cerebral ischemia. International Journal of Pharmaceutics, 531(1), 90-100.

79. Ferrer, I., Krupinski, J., Goutan, E., Marti, E., Ambrosio, S., \& Arenas, E. (2001). Brain-derived neurotrophic factor reduces cortical cell death by ischemia after middle cerebral artery occlusion in the rat. Acta Neuropathologica, 101(3), 229-238.

80. Endres, M., Fan, G., Hirt, L., Fujii, M., Matsushita, K., Liu, X., et al. (2000). Ischemic brain damage in mice after selectively modifying BDNF or NT4 gene expression. Journal of Cerebral Blood Flow \& Metabolism, 20(1), 139-144.

81. Yamashita, K., Wiessner, C., Lindholm, D., Thoenen, H., \& Hossmann, K.-A. (1997). Post-occlusion treatment with BDNF 
reduces infarct size in a model of permanent occlusion of the middle cerebral artery in rat. Metabolic Brain Disease, 12(4), 271-280.

82. Zhang, Y., \& Pardridge, W. M. (2006). Blood-brain barrier targeting of BDNF improves motor function in rats with middle cerebral artery occlusion. Brain Research, 1111(1), 227-229.

83. Schabitz, W.-R., Berger, C., Kollmar, R., Seitz, M., Tanay, E., Kiessling, M., et al. (2004). Effect of brain-derived neurotrophic factor treatment and forced arm use on functional motor recovery after small cortical ischemia. Stroke, 35(4), 992-997.

84. Andsberg, G., Kokaia, Z., Klein, R. L., Muzyczka, N., Lindvall, O., \& Mandel, R. J. (2002). Neuropathological and behavioral consequences of adeno-associated viral vector-mediated continuous intrastriatal neurotrophin delivery in a focal ischemia model in rats. Neurobiology of Disease, 9(2), 187-204.

85. Benedek, A., Moricz, K., Juranyi, Z., Gigler, G., Levay, G., Harsing, L. G. Jr., et al. (2006). Use of TTC staining for the evaluation of tissue injury in the early phases of reperfusion after focal cerebral ischemia in rats. Brain Research, 1116(1), 159-165.

86. Zille, M., Farr, T. D., Przesdzing, I., Muller, J., Sommer, C., Dirnagl, U., et al. (2012). Visualizing cell death in experimental focal cerebral ischemia: promises, problems, and perspectives. Journal of Cerebral Blood Flow \& Metabolism, 32(2), 213-231.

87. Tureyen, K., Vemuganti, R., Sailor, K. A., \& Dempsey, R. J. (2004). Infarct volume quantification in mouse focal cerebral ischemia: a comparison of triphenyltetrazolium chloride and cresyl violet staining techniques. Journal of Neuroscience Methods, 139(2), 203-207.

88. Ding, G. L., Chopp, M., Li, L., Zhang, L., Zhang, Z. G., Li, Q. J., et al. (2014). Magnetic resonance imaging of stroke in the rat. $B o$ Pu Xue Za Zhi, 31(1), 116-132.

89. Lu, H., Liu, X., Zhang, N., Zhu, X., Liang, H., Sun, L., et al. (2016). Neuroprotective effects of brain-derived neurotrophic factor and noggin-modified bone mesenchymal stem cells in focal cerebral ischemia in rats. Journal of Stroke and Cerebrovascular Diseases, 25(2), 410-418.

90. Patapoutian, A., \& Reichardt, L. F. (2001). Trk receptors: mediators of neurotrophin action. Current Opinion in Neurobiology, 11(3), 272-280.

91. Li, X., Yang, Z., \& Zhang, A. (2009). The effect of neurotrophin$3 /$ chitosan carriers on the proliferation and differentiation of neural stem cells. Biomaterials, 30(28), 4978-4985.

92. Lu, H., Hao, Z., Jiao, Q., Xie, W., Zhang, J., Lu, Y., et al. (2011). Neurotrophin-3 gene transduction of mouse neural stem cells promotes proliferation and neuronal differentiation in organotypic hippocampal slice cultures. Medical Science Monitor, 17(11), BR305.

93. Ohtsuka, M., Fukumitsu, H., \& Furukawa, S. (2009). Neurotrophin-3 stimulates neurogenetic proliferation via the extracellular signal-regulated kinase pathway. Journal of Neuroscience Research, 87(2), 301-306.

94. Shimazu, K., Zhao, M., Sakata, K., Akbarian, S., Bates, B., Jaenisch, R., et al. (2006). NT-3 facilitates hippocampal plasticity and learning and memory by regulating neurogenesis. Learning \& Memory, 13(3), 307-315.

95. Cristofaro, B., Stone, O. A., Caporali, A., Dawbarn, D., Ieronimakis, N., Reyes, M., et al. (2010). Neurotrophin-3 is a novel angiogenic factor capable of therapeutic neovascularization in a mouse model of limb ischemia. Arteriosclerosis, Thrombosis, and Vascular Biology, 30(6), 1143-1150.

96. Wang, Y., Lin, S.-Z., Chiou, A.-L., Williams, L. R., \& Hoffer, B. J. (1997). Glial cell line-derived neurotrophic factor protects against ischemia-induced injury in the cerebral cortex. Journal of Neuroscience, 17(11), 4341-4348.

97. Kobayashi, T., Ahlenius, H., Thored, P. R., Kobayashi, R., Kokaia, Z., \& Lindvall, O. (2006). Intracerebral infusion of glial cell line-derived neurotrophic factor promotes striatal neurogenesis after stroke in adult rats. Stroke, 37(9), 2361-2367.

98. Greenberg, D. A., \& Jin, K. (2013). Vascular endothelial growth factors (VEGFs) and stroke. Cellular and Molecular Life Sciences, 70(10), 1753-1761.

99. Kaya, D., Gürsoy-Özdemir, Y., Yemisci, M., Tuncer, N., Aktan, S., \& Dalkara, T. (2005). VEGF protects brain against focal ischemia without increasing blood-brain permeability when administered intracerebroventricularly. Journal of Cerebral Blood Flow \& Metabolism, 25(9), 1111-1118.

100. Sun, Y., Jin, K., Xie, L., Childs, J., Mao, X. O., Logvinova, A., et al. (2003). VEGF-induced neuroprotection, neurogenesis, and angiogenesis after focal cerebral ischemia. The Journal of Clinical Investigation, 111(12), 1843-1851.

101. Ward, N. L., \& Lamanna, J. C. (2004). The neurovascular unit and its growth factors: coordinated response in the vascular and nervous systems. Neurological Research, 26(8), 870-883.

102. Du, H., Li, P., Pan, Y., Li, W., Hou, J., Chen, H., et al. (2010). Vascular endothelial growth factor signaling implicated in neuroprotective effects of placental growth factor in an in vitro ischemic model. Brain Research, 1357, 1-8.

103. Freitas-Andrade, M., Carmeliet, P., Charlebois, C., Stanimirovic, D. B., \& Moreno, M. J. (2012). PIGF knockout delays brain vessel growth and maturation upon systemic hypoxic challenge. Journal of Cerebral Blood Flow \& Metabolism, 32(4), 663-675.

104. Shi, H. (2009). Hypoxia inducible factor 1 as a therapeutic target in ischemic stroke. Current Medicinal Chemistry, 16(34), 45934600.

105. Davis, C. K., Jain, S. A., Bae, O.-N., Majid, A., \& Rajanikant, G. (2019). Hypoxia mimetic agents for ischemic stroke. Frontiers in Cell and Developmental Biology, 6, 175.

106. Guillemot, F., \& Zimmer, C. (2011). From cradle to grave: the multiple roles of fibroblast growth factors in neural development. Neuron, 71(4), 574-588.

107. Lin, D. A., \& Finklestein, S. P. (1997). Review: Basic fibroblast growth factor: a treatment for stroke? The Neuroscientist, 3(4), 247-250.

108. Zeng, W., Ju, R., \& Mao, M. (2015). Therapeutic potential of hepatocyte growth factor against cerebral ischemia. Experimental and Therapeutic Medicine, 9(2), 283-288.

109. Lee, H. J., Kim, K. S., Kim, E. J., Choi, H. B., Lee, K. H., Park, I. H., et al. (2007). Brain transplantation of immortalized human neural stem cells promotes functional recovery in mouse intracerebral hemorrhage stroke model. Stem Cells, 25(5), 1204-1212.

110. Li, M., Hale, J. S., Rich, J. N., Ransohoff, R. M., \& Lathia, J. D. (2012). Chemokine CXCL12 in neurodegenerative diseases: an SOS signal for stem cell-based repair. Trends in Neurosciences, 35(10), 619-628.

111. Shichinohe, H., Kuroda, S., Yano, S., Hida, K., \& Iwasaki, Y. (2007). Role of SDF-1/CXCR4 system in survival and migration of bone marrow stromal cells after transplantation into mice cerebral infarct. Brain Research, 1183, 138-147.

112. Hill, W. D., Hess, D. C., Martin-Studdard, A., Carothers, J. J., Zheng, J., Hale, D., et al. (2004). SDF-1 (CXCL12) is upregulated in the ischemic penumbra following stroke: association with bone marrow cell homing to injury. Journal of Neuropathology \& Experimental Neurology, 63(1), 84-96.

113. Kyurkchiev, D., Bochev, I., Ivanova-Todorova, E., Mourdjeva, M., Oreshkova, T., Belemezova, K., et al. (2014). Secretion of immunoregulatory cytokines by mesenchymal stem cells. World Journal of Stem Cells, 6(5), 552.

114. Liesz, A., Bauer, A., Hoheisel, J. D., \& Veltkamp, R. (2014). Intracerebral interleukin-10 injection modulates post-ischemic neuroinflammation: an experimental microarray study. Neuroscience Letters, 579, 18-23. 
115. De Bilbao, F., Arsenijevic, D., Moll, T., Garcia-Gabay, I., Vallet, P., Langhans, W., et al. (2009). In vivo over-expression of interleukin-10 increases resistance to focal brain ischemia in mice. Journal of Neurochemistry, 110(1), 12-22.

116. Fan, L., Lin, C., Zhuo, S., Chen, L., Liu, N., Luo, Y., et al. (2009). Transplantation with survivin-engineered mesenchymal stem cells results in better prognosis in a rat model of myocardial infarction. European Journal of Heart Failure, 11(11), 1023-1030.

117. Fiore, R., Siegel, G., \& Schratt, G. (2008). MicroRNA function in neuronal development, plasticity and disease. Biochimica et Biophysica Acta (BBA)-Gene Regulatory Mechanisms, 1779(8), 471-478.

118. Ghosh, S., Brown, A. M., Jenkins, C., \& Campbell, K. (2020). Viral vector systems for gene therapy: a comprehensive literature review of progress and biosafety challenges. Applied Biosafety, 25(1), 7-18.

119. Al-Dosari, M. S., \& Gao, X. (2009). Nonviral gene delivery: principle, limitations, and recent progress. American Association of Pharmaceutical Scientists Journal, 11(4), 671-681.

120. Pandamooz, S., Salehi, M. S., Zibaii, M. I., Ahmadiani, A., Nabiuni, M., \& Dargahi, L. (2018). Epidermal neural crest stem cell-derived glia enhance neurotrophic elements in an ex vivo model of spinal cord injury. Journal of Cellular Biochemistry, 119(4), 3486-3496.

121. Hu, Y. F., Gourab, K., Wells, C., Clewes, O., Schmit, B. D., \& Sieber-Blum, M. (2010). Epidermal neural crest stem cell (EPINCSC)-mediated recovery of sensory function in a mouse model of spinal cord injury. Stem Cell Reviews and Reports, 6(2), 186198.

122. Pandamooz, S., Naji, M., Alinezhad, F., Zarghami, A., \& Pourghasem, M. (2013). The influence of cerebrospinal fluid on epidermal neural crest stem cells may pave the path for cell-based therapy. Stem Cell Research \& Therapy, 4(4), 84.

123. Ganguly, P., El-Jawhari, J. J., Giannoudis, P. V., Burska, A. N., Ponchel, F., \& Jones, E. A. (2017). Age-related changes in bone marrow mesenchymal stromal cells: a potential impact on osteoporosis and osteoarthritis development. Cell Transplant, 26(9), $1520-1529$.

124. Moghadasi Boroujeni, S., Koontz, A., Tseropoulos, G., Kerosuo, L., Mehrotra, P., Bajpai, V. K., et al. (2019). Neural crest stem cells from human epidermis of aged donors maintain their multipotency in vitro and in vivo. Scientific Reports, 9(1), 9750.

125. Baharvand, Z., Nabiuni, M., Tahmaseb, M., Amini, E., \& Pandamooz, S. (2020). Investigating the synergic effects of valproic acid and crocin on BDNF and GDNF expression in epidermal neural crest stem cells. Acta Neurobiologiae Experimentalis, 80(1), 38-46.

126. Pandamooz, S., Salehi, M. S., Safari, A., Azarpira, N., Heravi, M., Ahmadiani, A., et al. (2019). Enhancing the expression of neurotrophic factors in epidermal neural crest stem cells by valproic acid: A potential candidate for combinatorial treatment. Neuroscience Letters, 704, 8-14.

127. Pandamooz, S., Jafari, A., Salehi, M. S., Jurek, B., Ahmadiani, A., Safari, A., et al. (2020). Substrate stiffness affects the morphology and gene expression of epidermal neural crest stem cells in a short term culture. Biotechnology and Bioengineering, 117(2), 305317.

128. Salehi, M. S., Borhani-Haghighi, A., Pandamooz, S., Safari, A., Dargahi, L., Dianatpour, M., et al. (2019). Dimethyl fumarate upregulates expression of major neurotrophic factors in the epidermal neural crest stem cells. Tissue and Cell, 56, 114-120.

129. Pandamooz, S., Jurek, B., Salehi, M. S., Mostaghel, M., Miyan, J. A., Dianatpour, M., et al. (2021). The implementation of preconditioned epidermal neural crest stem cells to combat ischemic stroke. Comment on Othman, F.A.; Tan, S.C. Preconditioning strategies to enhance neural stem cell-based therapy for ischemic stroke. Brain Sciences, 11(5), 653. https://doi.org/10.3390/ brainsci11050653.

130. Neirinckx, V., Coste, C., Rogister, B., \& Wislet-Gendebien, S. (2013). Concise review: adult mesenchymal stem cells, adult neural crest stem cells, and therapy of neurological pathologies: a state of play. Stem Cells Translational Medicine, 2(4), 284-296.

131. Li, Y., Yao, D., Zhang, J., Liu, B., Zhang, L., Feng, H., et al. (2017). The effects of epidermal neural crest stem cells on local inflammation microenvironment in the defected sciatic nerve of rats. Frontiers in Molecular Neuroscience, 10, 133.

132. Zhang, L., Li, B., Liu, B., \& Dong, Z. (2019). Co-transplantation of epidermal neural crest stem cells and olfactory ensheathing cells repairs sciatic nerve defects in rats. Frontiers in Cellular Neuroscience, 13, 253.

133. Pandamooz, S., Salehi, M. S., Nabiuni, M., Dargahi, L., \& Pourghasem, M. (2016). Evaluation of epidermal neural crest stem cells in organotypic spinal cord slice culture platform. Folia Biologica (Praha), 62(6), 263-267.

134. Pandamooz, S., Jurek, B., Meinung, C. P., Baharvand, Z., Shahem-Abadi, A. S., Haerteis, S., et al. (2021). Experimental models of SARS-CoV-2 infection: possible platforms to study COVID-19 pathogenesis and potential treatments. Annual Review of Pharmacology and Toxicology. DOI:https://doi.org/ 10.1146/annurev-pharmtox-121120-012309.

135. Salehi, M. S., Pandamooz, S., \& Jurek, B. (2021). Epidermal neural crest stem cells as a perspective for COVID-19 treatment. Stem Cell Reviews and Reports, 17(1), 291-292.

136. Negoro, T., Okura, H., Maehata, M., Hayashi, S., Yoshida, S., Takada, N., et al. (2019). Trends in clinical trials for stroke by cell therapy: data mining ClinicalTrials.gov and the ICTRP portal site. NPJ Regenerative Medicine, 4, 20.

137. Wechsler, L. R., Bates, D., Stroemer, P., Andrews-Zwilling, Y. S., \& Aizman, I. (2018). Cell therapy for chronic stroke. Stroke, 49(5), 1066-1074.

138. Steinberg, G. K., Kondziolka, D., Wechsler, L. R., Lunsford, L. D., Coburn, M. L., Billigen, J. B., et al. (2016). Clinical outcomes of transplanted modified bone marrow-derived mesenchymal stem cells in stroke: a phase 1/2a study. Stroke, 47(7), 1817-1824.

139. Stepanenko, A. A., \& Heng, H. H. (2017). Transient and stable vector transfection: Pitfalls, off-target effects, artifacts. Mutation Research, 773, 91-103.

Publisher's Note Springer Nature remains neutral with regard to jurisdictional claims in published maps and institutional affiliations. 